\title{
Cocoa Polyphenols and Their Potential Benefits for Human Health
}

\author{
I. Andújar, M. C. Recio, R. M. Giner, and J. L. Ríos \\ Departament de Farmacologia, Facultat de Farmàcia, Universitat de València, Avenida Vicent Andrés Estellés s/n, \\ 46100 Burjassot, Valencia, Spain \\ Correspondence should be addressed to J. L. Ríos, riosjl@uv.es
}

Received 14 February 2012; Revised 18 May 2012; Accepted 31 May 2012

Academic Editor: Luciano Pirola

Copyright ( $\odot 2012$ I. Andújar et al. This is an open access article distributed under the Creative Commons Attribution License, which permits unrestricted use, distribution, and reproduction in any medium, provided the original work is properly cited.

This paper compiles the beneficial effects of cocoa polyphenols on human health, especially with regard to cardiovascular and inflammatory diseases, metabolic disorders, and cancer prevention. Their antioxidant properties may be responsible for many of their pharmacological effects, including the inhibition of lipid peroxidation and the protection of LDL-cholesterol against oxidation, and increase resistance to oxidative stress. The phenolics from cocoa also modify the glycemic response and the lipid profile, decreasing platelet function and inflammation along with diastolic and systolic arterial pressures, which, taken together, may reduce the risk of cardiovascular mortality. Cocoa polyphenols can also modulate intestinal inflammation through the reduction of neutrophil infiltration and expression of different transcription factors, which leads to decreases in the production of proinflammatory enzymes and cytokines. The phenolics from cocoa may thus protect against diseases in which oxidative stress is implicated as a causal or contributing factor, such as cancer. They also have antiproliferative, antimutagenic, and chemoprotective effects, in addition to their anticariogenic effects.

\section{Introduction}

Plant phenols from numerous plant species are being actively studied as potential treatments for various metabolic and cardiovascular diseases. For example, resveratrol from red wine $[1,2]$, epigallocathechin-3-gallate from green tea [35], curcumin from turmeric [6], and quercetin [7-12] from different sources have all been studied as potential therapeutic agents, to induce weight loss, lower blood pressure, attenuate glucose levels and insulin resistance (resveratrol), and improve hemoglobin $\mathrm{A} 1 \mathrm{c}$ and lipid profile in humans (epigallocathechin-3-gallate). Other studies also carried out in humans have shown the beneficial effects of grape seeds, chokeberries, coffee, carob, and cocoa [13]. This paper reviews the most recent research on this last substance and its potential benefits for human health.

Since the seventeenth century, cocoa and chocolate have been described as potential medicines. In Europe, various historical documents refer to chocolate's medicinal value; thus, although it was drunk as a beverage with a pleasurable taste, it was primarily eaten as a food to treat a number of disorders, including angina and heart pain [14]. Today, Theobroma cacao L. (Sterculiaceae) and its products are consumed worldwide and are studied mainly because of the antioxidant and antiradical properties in vitro of some of their polyphenolic constituents, specially procyanidins and flavan3-ols [15]. Many studies have described cocoa phenolics as being bioactive compounds, especially prominent for their metabolic and cardiovascular effects. These effects are due, in part, to the antioxidant [16] and antiradical properties of cocoa phenolics [17], which increase the plasma level of antioxidants to prevent the oxidation of LDL-cholesterol [18]. Along with their known antiplatelet effects [19], these particular properties are related to the protective mechanism of cocoa phenolics in heart disease [18]. Other relevant properties include their ability to modulate the immune response [20-24] and their anti-inflammatory [25-27] and anticarcinogenic properties $[26,28]$. In this paper, we have focused on the beneficial effects of cocoa polyphenols on human health, especially with regard to cardiovascular and inflammatory diseases, metabolic disorders, and cancer prevention as well as on their antioxidant properties. 


\section{Polyphenols Content in Cocoa}

Cocoa contains about 380 known chemicals, 10 of which are psychoactive compounds. In their natural state, cocoa beans are virtually inedible because of their high concentration of polyphenols, which gives them an extremely bitter flavor. In a final cocoa product such as chocolate, polyphenol content might decrease from $100 \%$ to $10 \%$ throughout the different manufacturing processes [29]. For this reason, various authors have focused on the effects of polyphenolenriched extracts from cocoa [27, 30-32].

Wollgast and Anklam [15] reviewed the polyphenol content of cocoa depending on its origin and the manufacturing process of the final product. Three groups of polyphenols can be identified in cocoa beans: catechins, which constitute about $37 \%$ of the polyphenol content in the beans, anthocyanidins (about 4\%), and proanthocyanidins (about 58\%). Of the catechins, (-)-epicatechin is the most abundant (up to $35 \%$ ), while $(+)$-catechin, $(+)$-gallocatechin, and (-)-epigallocatechin are present in smaller quantities (Figure 1). In the case of anthocyanidins, the main compounds are cyanidin-3- $\alpha$-L-arabinoside and cyanidin-3- $\beta$-D-galactoside, while in the case of procyanidins, the main compounds are dimers, trimers, or oligomers of flavan-3,4-diol linked by $4 \rightarrow 8$ or $4 \rightarrow 6$ bonds. Of these, the main procyanidins are B1, B2, B3, B4, B5, $\mathrm{C} 1$, and $\mathrm{D}$. The proportions of these derivatives usually change during the manufacturing process. For example, in the dried, fat-free mass of fresh cocoa beans, the total soluble polyphenol content is $15-20 \%$, which is equivalent to $6 \%$ in air-dried, nondefatted cocoa beans. In contrast, it is only about $5 \%$ in fermented, nondefatted beans because during the fermentation process epicatechin and soluble polyphenol content is reduced by approximately 10 to $20 \%$, anthocyanidins disappear, and procyanidins decrease 3- to 5fold. There is also a great amount of variation in the phenolic content of cocoa depending on its origin. For example, (-)catechin concentration in fermented, defatted cocoa beans varies from $16.52 \mathrm{mg} / \mathrm{g}$ in Costa Rican cocoa to $2.66 \mathrm{mg} / \mathrm{g}$ in cocoa grown in Jamaica.

\section{Bioavailability of Phenolics from Cocoa}

There is a great controversy surrounding the bioavailability of phenolics in general and of cocoa derivatives in particular. For example, epicatechin is well absorbed, with a maximum plasma concentration at around $2 \mathrm{~h}$ and with approximately $20 \%$ of consumed epicatechin being excreted in the urine [33]. In the case of dimers, their presence has been also described in plasma. For example, Holt et al. [34] described the presence of procyanidin dimers, especially B2 (epicatechin-(4 $\beta-8)$-epicatechin) in peripheral blood of healthy adults who had consumed a cocoa beverage.

3.1. Gastric Degradation of Cocoa Phenolics. There have been contradictory findings concerning the gastric stability of phenols from cocoa. For example, Spencer et al. [35] reported that, in the acidic environment of the gastric milieu, procyanidin oligomers are hydrolyzed to mixtures of epicatechin monomers and dimers. However, Rios et al. [36] observed that, during gastric transit, procyanidins were remarkably stable in the stomach environment and reached the small intestine intact, available for absorption or metabolism. In addition, their limited absorption in the small intestine could influence the digestive process or the physiology of the gut through direct interaction with the gut mucosa and gut lumen solutes. Consequently, some of the health effects of procyanidins may be associated with the formation by microflora of low-molecular-weight metabolites once the procyanidins reach the colon. This hypothesis has been corroborated by Gonthier et al. [37], who demonstrated that while proanthocyanidins of high molecular weight are not present in plasma or urine, the monomers and aromatic acids produced during their metabolism by intestinal microflora can be found in the latter. These researchers also demonstrated that catechin is well absorbed in the small intestine, with recoveries of 20 $40 \%$.

3.2. Intestinal Absorption of Phenols from Cocoa. Ortega et al. [38] coupled an in vitro digestion method with a continuousflow dialyzed duodenal step to construct a model for examining the digestibility and bioaccessibility of polyphenols in cocoa food matrices. Their results show that the fat content of the cocoa samples tested enhances the digestibility of some phenolic compounds, especially procyanidins, during duodenal digestion. The possible mechanism is probably related to the fat fraction's ability to interact with certain phenol compounds following a better micellization of the digested phenols.

A human bioavailability trial with chocolate polyphenols using $40 \mathrm{~g}$ of dark chocolate $(892 \mathrm{mg}$ of total polyphenols expressed as gallic acid equivalent and $82 \mathrm{mg}$ of epicatechin) showed that epicatechin was indeed absorbed into the blood. The compound was detectable in plasma as glucuronideconjugated metabolites and sulfate groups after $2 \mathrm{~h}$ and was still present after $8 \mathrm{~h}$. The clearance of epicatechin from the plasma compartment was very fast, with an elimination $t_{1 / 2}$ of 1.9 and $2.3 \mathrm{~h}$ for 40 and $80 \mathrm{~g}$ of chocolate, respectively [29].

Manach et al. [39] found that the metabolism of simple phenols occurs via a common pathway, being absorbed in the small intestine, and oligomers larger than trimers are unlikely to be absorbed in the small intestine in their native forms. In vitro experiments using single layers of Caco-2 cells as a model of absorption in the small intestine have corroborated the in vivo studies because they showed that only the dimers and trimers of flavan-3-ols are able to cross the intestinal epithelium; thus, procyanidin B2 is poorly absorbed in rats whereas procyanidin B3 is not absorbed at all [39].

In a study on the bioavailability of cocoa polyphenols in healthy volunteers, Tomás-Barberán et al. [30] demonstrated that the flavonoid composition (mainly flavanol monomers and dimers) of cocoa powder can be enhanced through improved processing of the raw material and that these flavanol-enriched samples lead to increases in the cocoa flavan-3-ols present in plasma and urine, thus increasing their bioavailability. 
<smiles>Oc1cc(O)c2c(c1)O[C@H](c1ccc(O)c(O)c1)[C@H](O)C2</smiles>

(-)-catechin

(a)<smiles>Oc1cc(O)c2c(c1)O[C@H](c1ccc(O)c(O)c1)[C@H](O)C2</smiles>

(c)<smiles>Oc1cc(O)c2c(c1)O[C@H](c1cc(O)c(O)c(O)c1)[C@H](O)C2</smiles>

(+)-epigallocatechin

(e)<smiles>Oc1cc(O)c2c(c1)O[C@H](c1ccc(O)c(O)c1)[C@H](O)[C@H]2c1c(O)cc(O)c2c1O[C@H](c1ccc(O)c(O)c1)[C@H](O)C2</smiles>

(g)<smiles>Oc1cc(O)c2c(c1)O[C@H](c1ccc(O)c(O)c1)[C@H](O)C2</smiles>

(+)-catechin

(b)<smiles>Oc1cc(O)c2c(c1)O[C@H](c1ccc(O)c(O)c1)[C@H](O)C2</smiles>

(d)<smiles>O=C(O[C@H]1Cc2c(O)cc(O)cc2O[C@@H]1c1cc(O)c(O)c(O)c1)c1cc(O)c(O)c(O)c1</smiles>

(-)-epigallocatechin gallate

(f)<smiles>Oc1cc(O)c2c(c1)O[C@H](c1ccc(O)c(O)c1)[C@H](O)[C@H]2c1c(O)cc(O)c2c1O[C@H](c1ccc(O)c(O)c1)[C@H](O)C2</smiles>

(h)

FIgURe 1: Continued. 


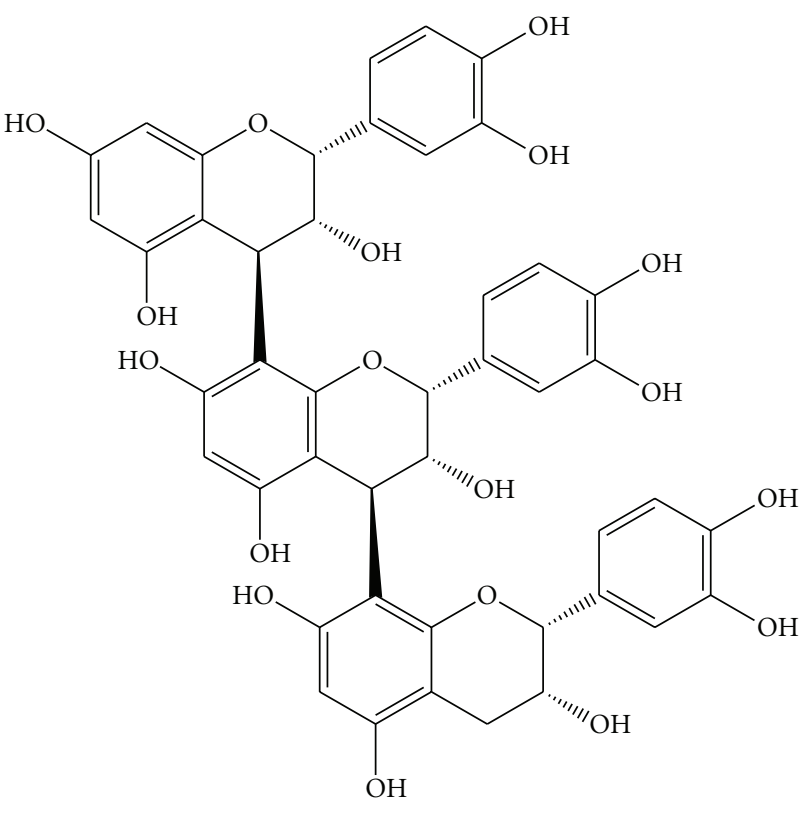

Procyanidin $\mathrm{C} 1$

(i)

Figure 1: Chemical structure of major cocoa phenolics.

\section{Antioxidant Properties of Cocoa Phenolics}

4.1. Scavenging Activity. Cocoa has more phenolics and higher antioxidant capacity than green tea, black tea, or red wine. In fact, Lee et al. [40] found that cocoa contains $611 \mathrm{mg} / \mathrm{serving}$ of gallic acid equivalents and $564 \mathrm{mg} /$ serving of epicatechin equivalents. The values for gallic acid equivalents were 1.8, 3.7, and 4.9 higher than those obtained for red wine, green tea, and black tea, respectively, while the epicatechin equivalents were 3.5, 12.0, and 16.6, respectively, for the same beverages. The values for antioxidant activity, measured with the aid of $2,2^{\prime}$ azino-bis(3-ethylbenzthiazoline-6-sulphonic acid) $\left(\mathrm{ABTS}^{+}\right)$ and 2,2-diphenyl-1-pycrylhydrazyl (DPPH) methods, were 1128 and $836 \mathrm{mg} /$ serving, respectively, expressed as vitamin $\mathrm{C}$ equivalent antioxidant capacity. When compared against that of red wine, green tea, or black tea, the relative activity of cocoa was $1.8,2.5$, and 4.4 times higher, respectively, in the $\mathrm{ABTS}^{+}$test, and 1.7, 2.4, and 4.3 times higher, respectively, in the DPPH test. The authors thus concluded that on a perserving basis, cocoa has higher flavonoid content and antioxidant capacity than red wine (2 times), green tea (23 times), and black tea (4-5 times), respectively.

Schinella et al. [16] studied the antioxidant activity of different cocoa extracts and demonstrated their effects on different in vitro experimental models, proving that the antioxidant effects cannot be fully characterized with one single method. The extracts' scavenging capacity was measured as the ability to bleach the stable radicals DPPH and $\mathrm{ABTS}^{+}$, their reducing ability was assessed with the ferric reducing-antioxidant power (FRAP) assay, and their scavenging properties against $\mathrm{H}_{2} \mathrm{O}_{2}, \mathrm{HClO}$, and peroxynitrite were also evaluated. The extracts acted both as a free radical scavenger (DPPH, $\mathrm{ABTS}^{+}$, superoxide, hypochloride, and peroxinitrite) and a lipid peroxidation inhibitor way that was directly proportional to their polyphenol content. The extracts also inhibited superoxide production by polymorphonuclear leukocytes. These findings indicate that cocoa extracts may modify the biological functions of these cells, which are implicated in the initiation and maintenance of inflammation. The extracts also showed scavenging activity against peroxynitrite, both in the presence and in the absence of a physiological concentration of bicarbonate. Under physiological conditions, bicarbonate levels are usually high and significant amounts of nitrosoperoxycarbonate anion adduct can be produced; however, in inflamed tissues where the $\mathrm{pH}$ value is lower, different reactions may occur independent of the presence of $\mathrm{CO}_{2}$. Because peroxynitrite anion can attack a wide range of biological molecules, its inhibition can provide protection against the damage induced by this free radical.

In a previous study, Schroeder et al. [41] examined the effect of a specific cocoa flavanol, (-)-epicatechin in a cellular model (murine aortic endothelial cells) for examining its protective action against peroxynitrite effects, and found that while it effectively blocked the nitration of protein tyrosine residues by peroxynitrite $\left(\mathrm{IC}_{50}\right.$ value $=$ approximately $0.02 \mathrm{~mol}$ epicatechin/mol peroxynitrite), its ability to block the oxidative inactivation of glyceraldehyde-3-phosphate dehydrogenase or soybean lipoxygenase (LOX)-1 was not significant $\left(\mathrm{IC}_{50}>1 \mathrm{~mol}\right.$ epicatechin/mol peroxynitrite).

4.2. Lipid Peroxidation. Schinella et al. [16] evaluated the ability of cocoa powder to bring about lipid peroxidation 
in brain homogenates and human plasma using nonenzymatic generation systems. Cocoa powder inhibited lipid peroxidation in both the homogenates and the plasma but had no effect on the hydroxyl radical, nor did it exhibit ferrous chelating activity. Metal chelating capacity reduces the concentration of the catalyzing transition metal in lipid peroxidation. It has previously been reported that the chelation efficiency of some compounds with a phenyl group on $\mathrm{Fe}^{2+}$ depends on the number of hydroxyl groups on the benzene ring and that hydroxyl substitution in the ortho position results in a higher chelating effect. However, because the polyphenol-rich cocoa extract showed neither ferrous nor copper chelating activity, it most likely acts as a chainbreaking antioxidant.

Verstraeten et al. [42] studied the antioxidant and membrane effects of procyanidin B2 (dimer) and procyanidin C1 (trimer) from cocoa in phosphatidyl choline liposomes. Both procyanidins inhibited lipid oxidation of liposomes in a concentration $(0.33-5 \mu \mathrm{M})$-dependent manner; moreover, both compounds also increased the membrane surface potential. They did this by decreasing membrane fluidity, an effect that extended into the hydrophobic region of the bilayer, protecting the lipid bilayer from disruption by Triton X-100. Procyanidins can thus interact with membrane phospholipids, probably through their polar head group, to provide protection against the attack of oxidants and other molecules that challenge the integrity of the bilayer.

4.3. Resistance to Oxidative Stress. Martorell et al. [43] used model organisms to study the effect of cocoa polyphenols on resistance to oxidative stress. A protocol of acute oxidative stress was optimized in order to test the best conditions to induce oxidative damage in Saccharomyces cerevisiae: doses of $4 \mathrm{mg} / \mathrm{mL}$ of a polyphenol-enriched cocoa powder led to an increased resistance to hydrogen peroxide ( 2 and $3 \mathrm{mM}$ ) tolerance, similar to those observed in cells treated with vitamin C. To discard the possibility that this was a strain-related effect, the authors repeated the test with other strains belonging to $S$. cerevisiae species. To discover the metabolic target with which the polyphenol-enriched cocoa powder might interact, authors evaluated the transcriptional profile concluding that the protection upon oxidative stress is mediated at least by sirtuins in S. cerevisiae. In order to clarify the function of sirtuin proteins as metabolic targets of cocoa flavonoids, different trials were performed with a more complex model, the nematode Caenorhabditis elegans. Worms fed with the cocoa powder were more resistant toward the oxidative stressor hydrogen peroxide, increasing their survival rate from $36 \%$ to $53 \%$ and their lifespan in a $17 \%$ after being fed with the cocoa powder. However, mutant strains of the worm for sirtuin and for the transcription factor DAF1 did not show resistance to oxidative stress nor prolonged lifespan, suggesting that the effects of cocoa powder are mediated at least through these genes. This work highlights the potential of polyphenol-enriched cocoa powder as a functional ingredient with resistance to oxidative stress.

In a clinical study, Spadafranca et al. [44] investigated the effects of both dark chocolate $(860 \mathrm{mg}$ of polyphenols, of which $58 \mathrm{mg}$ were epicatechin) and white chocolate ( $5 \mathrm{mg}$ of polyphenols, undetectable epicatechin) on plasma epicatechin levels, DNA damage to mononuclear blood cells, and total plasma antioxidant activity in 20 healthy subjects who followed a balanced diet for 4 weeks. Detectable epicatechin levels were only observed $2 \mathrm{~h}$ after dark chocolate intake, at which timeless DNA damage to mononuclear blood cells was likewise observed, but both effects were no longer evident after $22 \mathrm{~h}$. No effect on total plasma antioxidant activity was noted. These results demonstrate that dark chocolate improves DNA resistance to oxidative stress in healthy subjects but that this effect is transient, probably due to flavonoid kinetics. Because oxidative stress not only affects both the inflammatory process and atherogenesis, but also has mutagenic power over the human genome, the protective effect of cocoa polyphenols may have important consequences for oncogene expression and cancer pathogenesis.

\section{Phenolics from Cocoa in Metabolic and Endocrine Disorders}

Cocoa extracts and cocoa procyanidins are potent inhibitors of key enzymes in the digestion of carbohydrates and lipids; these inhibitory activities are related not only to their polyphenol content, but also to the degree of polymerization of cocoa procyanidins, all of which are dramatically affected by the cocoa processing. For example, Gu et al. [45] assessed their inhibitory effects of different cocoa extracts against pancreatic $\alpha$-amylase, pancreatic lipase, and secreted phospholipase $\mathrm{A}_{2}\left(\mathrm{PLA}_{2}\right)$ in vitro and characterized the kinetics of this inhibition and demonstrated that cocoa extracts and the procyanidins found in them dose-dependently inhibited all three enzymes. They also observed that the inhibitory potency of cocoa procyanidins increases as a function of their degree of polymerization, but they did not examine whether cocoa extracts and/or cocoa procyanidins can inhibit digestive enzymes in vivo and affect related downstream pathways such as aberrant eicosanoid metabolism at dose levels achievable in the diet.

The principal aspects to be treated in this section are the effects of cocoa polyphenols on carbohydrate and lipoprotein metabolism.

5.1. Effects on Carbohydrate Metabolism. Hanhineva et al. [46] published an interesting review compiling the effect of different polyphenols, including flavonoids and proanthocyanidins, on carbohydrate metabolism at many levels. In animal models and in a limited number of human studies, polyphenols have been found to attenuate postprandial glycemic responses and fasting hyperglycemia while improving acute insulin secretion and insulin sensitivity. The possible mechanisms of action include inhibition of carbohydrate digestion and glucose absorption in the intestine, stimulation of insulin secretion from the pancreatic $\beta$ cells, modulation of glucose release from the liver, activation of insulin receptors and glucose uptake in the insulinsensitive tissues, and modulation of intracellular signaling 
pathways and gene expression. These positive effects on glucose homeostasis are also supported by epidemiological evidence on polyphenol-rich diets.

Grassi et al. [47] compared the effects of flavanol-rich dark chocolate and flavanol-free white chocolate with regard to endothelial function, insulin sensitivity, $\beta$-cell function, and blood pressure in a randomized crossover trial with 19 hypertensive patients with impaired glucose tolerance. The group of patients treated with flavanol-rich dark chocolate ( $100 \mathrm{~g} /$ day for 15 days) showed decreased insulin resistance and increased insulin sensitivity and $\beta$-cell function. Moreover, subjects taking flavanol-rich dark chocolate experienced decreases in systolic and diastolic blood pressure, increased flow-mediated dilation, and decreased total cholesterol and LDL-cholesterol with respect to the control group [47].

Similar effects were described by other authors when reviewing systematically the effect of cocoa polyphenols on cardiovascular risk factors. Shrime et al. [48] did a systematic review and meta-analysis of randomized, controlled trials to evaluate the effect of a flavonoid-rich cocoa fraction on cardiovascular risk factors and showed that the cocoa phenolics decreased insulin resistance and increased flowmediated vascular dilation, with a maximum effect observed at a flavonoid dose of $500 \mathrm{mg} / \mathrm{d}$.

Hooper et al. [49] in a systematic review of 42 acute or short-term chronic randomized controlled trials including 1297 patients demonstrated a significant reduction of different negative biomarkers of cardiovascular disease, such as insulin resistance. Some parameters were improved in patients after chronic and acute intake of chocolate or cocoa, with significant reductions in serum insulin, and in flowmediated dilatation. In addition, the reductions in diastolic blood pressure and mean arterial pressure were observed, as well as a slight but significant reduction of LDL-cholesterol and an increase of HDL-cholesterol levels. These effects will be reviewed in the following sections.

5.2. Effects on Lipoprotein Metabolism. Cocoa phenolics increase apolipoprotein (Apo) A1 and decrease ApoB production in both the human hepatoma cell line HepG2 and the human intestinal cell line Caco2. Cells incubated for $24 \mathrm{~h}$ in the presence of cocoa polyphenols such as $(-)$-epicatechin, $(+)$-catechin, procyanidin B2, procyanidin $\mathrm{C} 1$, and cinnamtannin $\mathrm{A} 2$ at $10 \mu \mathrm{M}$ increased both ApoA1 protein levels and mRNA expression, even though ApoB protein and mRNA expression decreased slightly. These effects were the result of the upregulation of the mature form of sterol regulatory element binding proteins (SREBPs) and increased LDL receptor activity induced by the cocoa polyphenols. As cholesterol metabolism is known to be regulated by several different mechanisms, it was hypothesized that cocoa polyphenols, like other plant polyphenols, may act via multiple pathways as a regulatory receptor agonist or ligand. The mechanism responsible for the increase in highdensity lipoprotein (HDL)-cholesterol associated with daily cocoa intake was also identified [50]. However, other authors have obtained somewhat contradictory results in clinical trials. Khan et al. [51] had previously evaluated the effects of chronic cocoa consumption ( $42 \mathrm{~g} /$ day for 4 weeks) on lipid profile, oxidized LDL particles, and plasma antioxidant vitamin concentrations in 42 high-risk volunteers in a randomized, crossover feeding trial. The analysis of $24 \mathrm{~h}$ urine revealed significant increases of phase II metabolites, including glucuronide and sulfate conjugates. The concentration of HDL-cholesterol was significantly higher after cocoa intake in comparison with the control group, which received only milk, while the oxidized LDL levels decreased. No significant changes were registered for total plasma cholesterol, triglycerides, LDL-cholesterol, ApoA1 and ApoB, lipoprotein concentrations, or the LDL/HDL-cholesterol ratio. Other biochemical parameters such as fibrinogen and homocysteine did not vary, and no significant changes were found in the plasma concentrations of vitamins $\mathrm{B}_{1}, \mathrm{~B}_{6}, \mathrm{~B}_{12}, \mathrm{C}$, and $\mathrm{E}$, or in plasma and intraerythrocyte folic acid concentrations. The authors studied the correlation between changes in polyphenols, lipids, and oxidized LDL measurements and observed higher increments in the urinary excretion of cocoa (-)-epicatechin metabolites. Regarding cocoa metabolites derived from intestinal microbial metabolism, an increase in the urinary excretion of 3-hydroxyphenylacetic and vanillic acids was observed in parallel with a significant increase in plasma HDL-cholesterol concentration and a decrease in plasma-oxidized LDL levels.

Jia et al. [52] studied the effect of cocoa on total cholesterol, LDL-cholesterol, and HDL-cholesterol in 8 trials involving 215 participants. Whereas LDL-cholesterol was significantly lowered and total cholesterol marginally lowered, no significant changes in HDL-cholesterol were observed after cocoa consumption. There was no evidence of a dose-effect relationship, of any effect in healthy subjects, or of any change in HDL-cholesterol. The authors concluded that short-term cocoa consumption significantly reduced blood cholesterol, but the changes depended on the amount of cocoa consumed and the health status of participants; indeed, there was no dose response and no effect in healthy participants. To assess the dose-response effect, Almoosawi et al. [53] carried out a randomized, single-blind, crossover study in which 14 overweight/obese subjects were randomized to take either $20 \mathrm{~g}$ of dark chocolate with $500 \mathrm{mg}$ of polyphenols and then $20 \mathrm{~g}$ of dark chocolate with $1000 \mathrm{mg}$ of polyphenols or vice versa. Participants followed each diet for 2 weeks separated by a 1-week washout period.

Mellor et al. [31] conducted a randomized, placebocontrolled double-blind crossover trial comparing the effects of chocolate with high polyphenol content $(16.6 \mathrm{mg}$ of epicatechins in $45 \mathrm{~g}$ of chocolate) with those of chocolate with low-polyphenol content $(<2 \mathrm{mg}$ of epicatechins in $45 \mathrm{~g}$ of chocolate) on lipid profiles, weight, and glycemic control in 12 individuals with type 2 diabetes on stable medication. HDL-cholesterol increased significantly with high polyphenol chocolate, with a decrease in the total cholesterol/HDL ratio and no changes in any of the other parameters under study. The authors concluded that high-polyphenol chocolate is effective in improving the atherosclerotic cholesterol profile in patients with diabetes by increasing HDLcholesterol and improving the cholesterol/HDL ratio without 
affecting weight, inflammatory markers, insulin resistance, or glycemic control. However, as stated above, marginally significant effects on LDL- and HDL-cholesterol were found by Hooper et al. [49], although there were no significant effects on total cholesterol, after acute or chronic intake. As a secondary analysis, they assessed the effects on body weight, body mass index, and waist circumference, but few trials reported these outcomes.

Some of these indices were recently evaluated by Shrime et al. [48] who studied the cardioprotective effects of a flavonoid-rich cocoa fraction. The most relevant risk factors evaluated were blood pressure, pulse, total cholesterol, HDL-cholesterol, LDL-cholesterol, triglycerides, body mass index, C-reactive protein, flow-mediated vascular dilation (FMD), fasting glucose, fasting insulin, serum isoprostane, and insulin sensitivity/resistance indices. Results showed that LDL-cholesterol decreased by $0.077 \mathrm{mmol} / \mathrm{L}$, and HDLcholesterol increased by $0.046 \mathrm{mmol} / \mathrm{L}$, whereas total cholesterol, triglycerides, and C-reactive protein remained the same.

\section{Phenolics from Cocoa in Cardiovascular Diseases}

Epidemiological studies demonstrate that regular dietary intake of cocoa polyphenols reduces the risk of coronary heart disease and stroke and is inversely associated with the risk of cardiovascular disease. This effect was described for first time in the Kuna Indians (Panama), who belong to one of the few cultures protected against the agedependent increase in blood pressure and the development of arterial hypertension. These healthy effects have been correlated with the consumption of high amounts of cocoa. Clinical studies revealed that, compared with other PanAmerican citizens, the Kunas have lower blood pressure rates and lower mortality resulting from cardiovascular events [54].

6.1. Effects on Arachidonic Acid Metabolism. The consumption of cocoa/chocolate increases plasma antioxidant capacity, diminishes platelet function and inflammation, and decreases diastolic and systolic arterial pressures. Currently available data indicate that daily consumption of cocoa-rich chocolate or polyphenol-enriched cocoa extracts could partially lower cardiovascular disease risk $[55,56]$. The mechanism by which the cardiovascular protection of cocoa polyphenols develops is complex, with different mediators and agents being implicated. For example, the effects of cocoa polyphenols on inflammatory mediators such as leukotrienes (LT), nitric oxide (NO) metabolism, and myeloperoxidase- (MPO-) induced modification of LDL indicate that the antioxidant properties of polyphenol-enriched cocoa extracts could be of great interest for developing therapies to prevent cardiovascular disease since oxidative modification of LDL appears to be crucial for atherogenesis. In fact, cocoa polyphenols decrease the plasma concentration of proinflammatory cysteinyl leukotrienes through inhibition of 5-LOX, as demonstrated by Sies et al. [57] in isolated recombinant human 5-LOX $\left(\mathrm{IC}_{50}\right.$ of $(-)$-epicatechin $\left.=22 \mu \mathrm{M}\right)$. Recombinant human platelet 12-LOX, a representative of another subfamily of mammalian lipoxygenases, also was inhibited by $(-)$-epicatechin $\left(\mathrm{IC}_{50}=15 \mu \mathrm{M}\right)$, therefore concluding that this compound and related flavan-3-ols are general inhibitors of mammalian LOX. The inhibition of human 5-LOX by cocoa flavonoids suggests that these compounds exert antileukotriene actions, which may confer a degree of anti-inflammatory, vasoprotective, and antibronchoconstrictory capacity because the principal metabolite of 5LOX, $\mathrm{LTB}_{4}$, causes neutrophils to adhere to endothelial cells, thus acting as a potent chemotactic agent for these and other inflammatory cells. It also stimulates the release of lysosomal enzymes and the generation of superoxide anion in neutrophils, while the cysteinyl-LTs increase vascular permeability and contract airway smooth muscle.

Another oxidant enzyme with pronounced effects on inflammation and atherogenesis is MPO, which has also been reported to act as an $\mathrm{NO}$ oxidase. In vitro, $\mathrm{MPO}$ is capable of binding to LDL, catalyzing oxidative modification and rendering it atherogenic. (-)-epicatechin and procyanidins have been shown to block the MPO/nitrite-mediated and peroxynitrite-mediated lipid peroxidation of LDL; for example, (-)-epicatechin is able to suppress it at concentrations as low as $0.1 \mu \mathrm{mol} / \mathrm{L}$ [58].

Unlike 5-LOX and platelet-type 12-LOX, the reticulocyte-type lipoxygenases (12-LOX and 15-LOX) are catalysts of enzymatic lipid peroxidation. Oxidative modification of LDL by 15-LOX-1, MPO, and peroxynitrite renders its atherogenicity and plays a relevant role in the early developmental stages of atherosclerotic lesions. Agents such as cocoa polyphenols that interfere with the oxidative modification of LDL should therefore be protective for vascular endothelium, including that of coronary arteries.

In conclusion, the inhibitory effects of cocoa polyphenols on 5-LOX and 15-LOX-1 may contribute to their beneficial actions [57].

6.2. Effects on NO Bioactivity. Cocoa phenols also promote the bioactivity of $\mathrm{NO}$ in vivo, which is critical for protecting the cardiovascular system. Sies et al. [57] compared the effects of cocoa beverages containing different contents of flavanols among selected volunteers, concluding that ingestion of flavanol-rich cocoa by individuals with diminished endothelial function led to an increase in the plasma NO concentration approaching the mean concentrations of healthy control subjects and doubled flow-mediated dilation after $2 \mathrm{~h}$. Plasma concentrations of NO were correlated with flowmediated dilation, which suggests that the improvement of endothelial function might be attributable to increased bioavailability of NO. In contrast, these changes did not occur among individuals who received either water or a low-flavanol cocoa drink, which excluded effects of beverage constituents other than flavanols. The NO-promoting effects of cocoa polyphenols may also contribute to a decrease in blood pressure because they interfere with $\mathrm{NO}$ metabolism at several levels. They especially favor the synthesis of NO 
and suppress deleterious metabolites such as superoxide, peroxynitrite, and $\mathrm{NO}_{2}$ [57].

As Corti et al. [54] cite, these compounds also induce NO-dependent vasodilation in the rat aorta and in the finger or forearm circulation of healthy humans or patients with cardiovascular risk factors. Cocoa lowers vascular arginase activity in human endothelial cells, augmenting local levels of L-arginine, which is then transformed into $\mathrm{NO}$ by endothelial nitric oxide synthase (eNOS). Once released, NO increases intracellular cyclic guanosine monophosphate (cGMP) concentrations, inducing a relaxation of vascular smooth muscle cells. NO not only leads to vasodilatation, but also prevents leukocyte adhesion and migration, smooth muscle cell proliferation, and platelet adhesion and aggregation. In patients with cardiovascular risk factors, including smoking, a cocoa drink high in flavonol content rapidly enhances the circulating pool of bioactive $\mathrm{NO}$ and augments flow-mediated vasodilation. Moreover, chronic consumption of a high-flavanol diet is associated with high urinary excretion of NO metabolites, which is consistent with augmented NO production or diminished degradation. Moreover, flavonoid-enriched cocoa results in regional changes in cerebral blood flow and an overall increased blood flow. In elderly humans on a high-flavanol diet, cerebral blood flow velocity in the middle cerebral artery has been shown to increase, suggesting that cocoa flavanols may protect against dementia and stroke [54]. The improvement of endothelial function is probably one of the mechanisms by which polyphenols confer cardiovascular protection. Indeed, polyphenols are able to induce NOmediated, endothelium-dependent relaxations in a large number of arteries, including the coronary artery. In some arteries they can also induce endothelium-derived hyperpolarizing factor (EDHF)-mediated relaxations. Taken together, these mechanisms may help explain the antihypertensive and cardioprotective effects of polyphenols in vivo [58].

6.3. Effects of Cocoa Phenolics on Other Mediators Implicated in Vascular Properties. Cocoa procyanidins are potent inhibitors of mitogen-activated protein kinase kinase (MEK) and membrane type-1 (MT1)-matrix metalloproteinase (MMP). They subsequently inhibit the expression and activation of pro-MMP-2 as well as the invasion and migration of human vascular smooth muscle cells (VSMCs). In fact, both cocoa procyanidin fraction $(3 \mu \mathrm{g} / \mathrm{mL})$ and procyanidin B2 $(5 \mu \mathrm{M})$ were found to strongly inhibit the thrombininduced activation and expression of pro-MMP-2 in VSMCs, the thrombin-induced invasion and migration of VSMCs, MT1-MMP activity, and the thrombin-induced phosphorylation of extracellular signal-regulated protein kinase (ERK) (but not that of MEK) in VSMCs. Kinase and pull-down data show that cocoa procyanidin fraction and procyanidin B2 inhibit MEK1 activity, binding directly with glutathioneS-transferase-MEK1. These results may partially explain the molecular action of cocoa's antiatherosclerotic effects [59].

There is evidence of the structure-activity relationship of endothelium-dependent vasodilator responses to procyanidins in isolated vessels. This is consistent with the hypothesis that these responses are mediated by a procyanidin receptor, which could represent an important target for new agents to treat endothelial dysfunction. Because this response involves signaling through superoxide or hydrogen peroxide, it could even be considered prooxidant. Flow-mediated dilatation also involves signaling through hydrogen peroxide. Hence, these findings bolster the hypothesis that procyanidins trigger an endothelial response similar to that of laminar shear stress [60].

In a controlled trial, Monagas et al. [32] evaluated the effects of chronic cocoa consumption on cellular and serum biomarkers related to atherosclerosis in 42 high-risk patients in a randomized crossover feeding trial. All subjects received $40 \mathrm{~g}$ cocoa powder with $500 \mathrm{~mL}$ skim milk per day or only $500 \mathrm{~mL}$ skim milk per day for 4 weeks. No significant changes in the expression of adhesion molecules on $\mathrm{T}$ lymphocyte surfaces were observed. However, in monocytes, the expression of VLA-4, CD40, and CD36 was significantly lower in the cocoa intake group compared to the control group. In addition, serum concentrations of the soluble endothelium-derived adhesion molecule P-selectin and intercellular adhesion molecule (ICAM)-1 were significantly lower after cocoa intake than after milk intake. The authors concluded that the intake of cocoa polyphenols may modulate inflammatory mediators in patients at high risk for cardiovascular disease; indeed, these anti-inflammatory effects may contribute to the overall benefits of cocoa consumption against atherosclerosis.

The vascular actions associated with transforming growth factor (TGF)- $\beta_{1}$ and homeostatic modulation of its production by flavan-3-ols and procyanidins from cocoa may constitute another mechanism by which phenolics from cocoa can potentially benefit cardiovascular health. In this context, Mao et al. [61] studied the effect of flavan-3-ols and procyanidins fractions (monomers through decamers) isolated from cocoa on the secretion of the cytokine TGF$\beta_{1}$ in resting human peripheral blood mononuclear cells (PBMCs) from 13 healthy subjects. When cells of individuals with low baseline levels of TGF- $\beta_{1}$ were stimulated by individual flavan-3-ol and procyanidin fractions $(25 \mu \mathrm{g} / \mathrm{mL})$, TGF- $\beta_{1}$ release was enhanced in the range of $16-66 \%$. The low-molecular-weight fractions ( $\leq$ pentamers) were more effective at augmenting TGF- $\beta_{1}$ secretion than their larger counterparts (hexamer or higher), with the monomer and dimer inducing the greatest increases (66\% and 68\%, resp.). In contrast, in the case high TGF- $\beta_{1}$ baseline subjects, the TGF- $\beta_{1}$ secretion was inhibited, being the inhibition most pronounced for trimmers through decamers $(28-42 \%$, resp.) and moderate for monomers to dimers (17-23\%, resp.). Given the vascular actions associated with TGF- $\beta_{1}$ release, this homeostatic modulation by cocoa polyphenols offers an additional mechanism by which polyphenol-rich foods can benefit cardiovascular health.

6.4. Cocoa Phenols and Cardiovascular Disease. Ding et al. [62] carried out a systematic review of experimental, observational, and clinical studies of the relationship between chocolate and cocoa and the risk of cardiovascular disease. The data from a total of 136 publications suggests that cocoa and chocolate may exert beneficial effects with regard 
to cardiovascular risk via various mechanisms, including lowering blood pressure, anti-inflammation, anti-platelet function, increasing HDL level while decreasing LDL oxidation. In addition, prospective studies of flavonoids suggest that the phenolic content of chocolate may reduce the risk of cardiovascular mortality.

Phenolics from cocoa also decrease the tendency of blood to clot. For example, an acute dose of flavanols and oligomeric procyanidins from cocoa powder was found to inhibit platelet activation and function for over $6 \mathrm{~h}$ in humans. In a blinded parallel-design study, 32 healthy subjects were assigned to consume $234 \mathrm{mg}$ cocoa phenolics a day [63].

6.5. Effects on Platelet Function. Platelet function was determined by measuring platelet aggregation, ATP release, and the expression of activation-dependent platelet antigens. After 28 days of treatment, cocoa polyphenol supplementation increased plasma epicatechin and catechin concentrations by $81 \%$ and $28 \%$, respectively, while decreasing platelet function. These findings are in agreement with results from studies that used higher doses of cocoa flavanols and procyanidins [63]. Moreover, cocoa decreases not only platelet aggregation, but also adhesion. The effects of cocoa polyphenols could thus be explained in part by their ability to reduce the ADP-induced expression of the activated conformation of glycoprotein IIb/IIIa surface proteins [54]. Various studies have indicated that dark chocolate induces coronary vasodilation, improves coronary vascular function, and decreases platelet adhesion. These immediate beneficial effects are paralleled by a significant reduction in serum oxidative stress and have been positively correlated with changes in serum epicatechin concentration. Flammer et al. [64] studied these effects on coronary vascular and platelet function in 22 heart transplant recipients in a doubleblind, randomized study. The ingestion of $40 \mathrm{~g}$ of flavonoidrich dark chocolate (containing $0.27 \mathrm{mg} / \mathrm{g}$ of catechin and $0.9 \mathrm{mg} / \mathrm{g}$ of epicatechin, with a total polyphenol content of $15.6 \mathrm{mg}$ of epicatechin equivalents per gram) increased coronary artery diameter, improved endothelium-dependent coronary vasomotion, and decreased platelet adhesion, all of which remained unchanged in the control group.

Carnevale et al. [65] carried out a crossover, single blind study with 20 healthy subjects and 20 smokers who received $40 \mathrm{~g}$ of dark (cocoa $>85 \%)$ or milk $($ cocoa $<35 \%)$ chocolate. Compared to healthy subjects, smokers showed enhancements in platelet recruitment, platelet formation of reactive oxygen species (ROS) and eicosanoids, and nicotinamide adenine dinucleotide phosphate (NADPH)-reduced oxidase (NOX)2 activation. In the dark chocolate group, platelet ROS, 8-iso-prostaglandin (PG) $\mathrm{F}_{2 \alpha}$, and NOX2 activation decreased significantly, but in the subgroup of healthy subjects taking dark chocolate, platelet variables did not change. No changes were detected in either of the groups treated with milk chocolate. The authors concluded that dark chocolate inhibits platelet function by lowering oxidative stress only in smokers; this effect seems to be dependent on its polyphenol content.
6.6. Effects on Arterial Hypertension. As discussed above, animal and human studies suggest that cocoa and chocolate could regulate NO bioavailability, affecting endothelial function and, in turn, blood pressure. Although these studies are not definitive and many questions remain, the body of evidence suggests that it is worth considering diets that can provide benefits to patients with high blood pressure; indeed, these benefits will be more significant in subjects that do not have their hypertension under control [66].

As mentioned above, significant reductions in diastolic blood pressure and mean arterial pressure after chronic intake were observed in Hooper's review [48].

Cienfuegos-Jovellanos et al. [67] evaluated the effects of various doses of a natural flavonoid-enriched cocoa powder (50-600 mg/kg) on spontaneously hypertensive rats. The polyphenol extract produced an antihypertensive effect in hypertensive rats without modifying the arterial blood pressure in normotensive rats. However, no dose-response effect was observed: the maximum effect on the systolic blood pressure of hypertensive rats was reached with $300 \mathrm{mg} / \mathrm{kg}$ of extract, while the maximum effect on the diastolic blood pressure, was achieved with a dose of $100 \mathrm{mg} / \mathrm{kg}$. In a complementary study, Almoosawi et al. [53] found that the $500 \mathrm{mg}$ polyphenol dose was equally effective in reducing systolic blood pressure, and diastolic blood pressure as the $1000 \mathrm{mg}$ polyphenol dose, which suggests that a saturation effect might occur with increased doses of polyphenols.

Akita et al. [68] studied the effect of dietary intake of cocoa polyphenols on heart rate, blood pressure, and plasma lipid concentrations. The area of atherosclerotic lesions in the aortas of the polyphenol-treated group was significantly smaller than in the control group. In addition, whereas the high-frequency power of heart rate variability of the rabbits in the standard diet group decreased significantly with ageing, there were no differences between long- and shortterm treatments in the polyphenol group. Moreover, cocoa liquor polyphenols preserved parasympathetic nervous tone, although this decreased significantly with ageing in the standard diet group. No differences in the plasma lipid concentrations were observed. The authors concluded that cocoa liquor polyphenols may play an important role in protecting cardiovascular function.

To date, epidemiological data on cocoa polyphenols has been scarce. Rimbach et al. [69] reviewed different relevant clinical trials and selected the results of five of them in which the following conclusions were established: in a cohort of elderly men, cocoa intake was inversely associated with blood pressure as well as with 15-year cardiovascular and all-cause mortality; a prospective study examined flavonoid intake and cardiovascular disease mortality in postmenopausal women; a meta-analysis of 133 studies on flavonoids, flavonoid-rich foods, and cardiovascular disease risk found a correlation between chocolate intake and increased flowmediated dilation along with reductions in both systolic and diastolic blood pressure; a cohort study involving over 1100 nondiabetic patients assessed the long-term effects of chocolate consumption amongst patients with established coronary heart disease; finally, a study conducted with patients surviving their first acute myocardial infarction 
found that chocolate consumption was associated with significant reductions in cardiac mortality and beneficial effects on vascular health. However, these studies raise many doubts. For example, the products used in controlled studies often contain much higher polyphenol contents than most commercially available products. It thus needs to be established whether the consumption of products with lower polyphenol content is associated with any health benefits in humans. Moreover, many of these studies have mainly been funded by industrial sponsors, and it must be remembered that the food industry is encouraged to label the flavonoid content on cocoa-derived products [69].

In a 6-month clinical trial carried out by Ried et al. [70] with 36 prehypertensive healthy adult volunteers, at content levels of $120-139$ and $80-89 \mathrm{mmHg}$, no significant differences were observed in the blood pressures of the treated and control groups. However, a marked difference in acceptability between the two treatment forms (chocolate or capsule) was observed due to the amount of chocolate that had to be eaten ( $50 \mathrm{~g}$ of dark chocolate every day). In contrast, other studies [71] have reported on blood pressure changes in response to flavanol-rich cocoa in healthy subjects as well as in prehypertensive and hypertensive patients, suggesting that the inclusion of moderate amounts of flavanolrich cocoa or chocolate in the daily diet may potentially ameliorate or delay the onset of hypertension. Indeed, it has been estimated that a $3 \mathrm{mmHg}$ reduction in systolic blood pressure reduces the relative risk of stroke mortality by $8 \%$, of coronary artery disease mortality by $5 \%$, and of all-cause mortality by $4 \%$.

Actis-Goretta et al. [72] examined the effects of different isolated polyphenols from cocoa on angiotensin converting enzyme activity; several procyanidins (dimer and hexamer) and epigallocatechin significantly inhibited the enzyme activity, whereas monomers, flavonols, phenolic acids, and resveratrol at similar concentrations showed no activity. Authors established three levels of $\mathrm{IC}_{50}$ : values in the $\mathrm{mM}$ range for monomeric flavan-3-ols, in the $100 \mu \mathrm{M}$ range for dimer and trimer, and in the $10 \mu \mathrm{M}$ range for larger procyanidins, although these concentrations should be interpreted with caution as they were estimated using nonphysiological in vitro conditions. These in vitro effects were correlated with the in vivo reductions in blood pressure observed in several experimental models [72].

Cherniack [13] reviewed the effects of polyphenols on metabolic syndrome and noted that eight patients with coronary artery disease who were given cocoa drinks containing a $375 \mathrm{mg}$ dose of cocoa polyphenols twice a day for 1 month had improved vasodilatory capacity in their brachial arteries and were able to produce larger numbers of endothelial progenitor cells. Moreover, the systolic blood pressure of subjects taking the larger dose cocoa decreased $4.2 \mathrm{mmHg}$, an effect which was not observed in the group that consumed only $9 \mathrm{mg}$ twice a day. In addition, meta-analyses of human trials have concluded that cocoa can lower systolic and diastolic blood pressure by 4.5 and 2.5 , respectively [13].

A meta-analysis with 10 randomized controlled trials comprising 297 individuals confirmed the blood pressurelowering capacity of flavanol-rich cocoa products in a larger set of trials than previously reported. Both the systolic and diastolic blood pressures decreased in either healthy normotensive adults or patients with prehypertension/stage 1 hypertension. However, significant statistical heterogeneity across studies was described [73].

In summary, critical attention must be paid to the flavanol content of cocoa foods since manufacturing processes significantly reduce its concentration in the final product. The high fat and sugar content of many cocoa snacks and confectionaries must also be taken into account. However, even with these limitations, the latest findings on the effects of flavonoid-rich cocoa are of clinical relevance and hold promise for the development of new, low calorie cocoa foods and beverages. Further research is needed to characterize the mechanisms of action leading to the final effects of cocoa. Also, before recommending cocoa products as a treatment option in hypertensive and at-risk patients, well-designed, long-term clinical trials are needed to definitively confirm the putative beneficial role of long-term consumption of flavanol-rich foods. Specific attention should be paid to clarifying questions concerning the most appropriate dose, the best targets, and eventual long-term and high-dose side effect profiles [69].

\section{Effects of Cocoa Phenolics on the Immune System}

Kenny et al. [21] demonstrated that cocoa oligomers are potent stimulators of both the innate immune system and early events in adaptive immunity. They supported their hypothesis with evidence that the chain length of flavanol fractions showed a significant effect on cytokine release from both unstimulated and LPS-stimulated PBMCs after $16 \mathrm{~h}$ treatment $(20 \mu \mathrm{g} / \mathrm{mL})$. For example, there was a marked increase in LPS-induced synthesis of interleukin (IL)- $1 \beta$, IL6 , IL-10, and TNF- $\alpha$ in the presence of long-chain flavanol fractions (hexamers to decamers). Both long- and shortchain flavanol fractions stimulated the production of granulocyte macrophage colony-stimulating factor (GM-CSF) in the absence of LPS and increased the expression of the B cell markers CD69 and CD83. However, different results were obtained by other authors using phytohemagglutinin A (PHA)-stimulated PBMCs, in which the production of these cytokines depended on the degree of polymerization. For example, IL-1 $\beta$ was suppressed by monomers to tetramers, but stimulated by pentamers to decamers, and TNF- $\alpha$ was clearly increased only by decamers [25]. These results indicate that some effects of cocoa polyphenols depend on their degree of polymerization as well as the agent used for cell stimulation.

\section{Anti-Inflammatory Properties of Phenolics from Cocoa}

Sies et al. [57] reviewed the effects of cocoa phenolics on inflammatory mediators such as leukotrienes. Some of these effects have been previously cited for their implication in cardiovascular diseases. They reported that (-)-epicatechin 
inhibits the dioxygenase and $\mathrm{LTA}_{2}$ synthase activities of 5-LOX, the first two consecutive steps in the conversion of arachidonic acid into various proinflammatory agents, including leukotrienes, which are catalyzed by the same enzyme. (-)-Epicatechin has also been shown to inhibit 15-LOX-1. When other cocoa products (e.g., oligomeric procyanidins) were tested as potential inhibitors, the authors observed that only small procyanidins (dimers to pentamers) showed effects similar to those of monomers. However, the pattern against 12-LOX-1 was quite different. The inhibitory potency first decreased from monomers to tetramers but then increased with the oligomer size, with the decamer being the most potent. These effects were also demonstrated in vivo. The subjects with a diet including polyphenol-rich cocoa products had lower levels of plasma leukotrienes $\mathrm{LTC}_{4}$, $\mathrm{LTD}_{4}$, and $\mathrm{LTE}_{4}$, along with increased levels of prostacyclin $2 \mathrm{~h}$ after treatment [25].

8.1. Effects on Proinflammatory Cytokine Release. Ramiro et al. [74] studied the effects of a cocoa extract on the secretion and RNA expression of various proinflammatory mediators by macrophages. Of these, monocyte chemoattractant protein (MCP)-1 and tumor necrosis factor (TNF)$\alpha$ were significantly and dose-dependently diminished by the extract. All cocoa flavonoids tested were capable of reducing MCP-1 secretion after $6 \mathrm{~h}$ of LPS activation. Thus, epicatechin $(100-200 \mu \mathrm{M}$, corresponding to $29-58 \mu \mathrm{g} / \mathrm{mL})$ reduced MCP-1 secretion, exhibiting an inhibition of up to $28 \%$; cocoa extract $(50 \mu \mathrm{g} / \mathrm{mL})$ also diminished MCP-1 secretion, and this effect was significantly stronger than that produced by epicatechin $(58 \mu \mathrm{g} / \mathrm{mL})$. Isoquercitrin $(5-40 \mu \mathrm{M}$, which represents $2.32-18.6 \mu \mathrm{g} / \mathrm{mL}$ ) was the most effective in lowering MCP-1 levels, causing a $28-65 \%$ dose-dependent decrease. As for TNF- $\alpha$, both epicatechin $(58 \mu \mathrm{g} / \mathrm{mL})$ and isoquercitrin $(18.6 \mu \mathrm{g} / \mathrm{mL})$ significantly reduced TNF- $\alpha$ secretion, achieving an inhibition of approximately $35 \%$ and $20 \%$, respectively. Cocoa extract $(50 \mu \mathrm{g} / \mathrm{mL})$ also significantly decreased TNF- $\alpha$ secretion by about $15 \%$. These effects may be produced, at least in part, at the transcriptional level. A $58 \mu \mathrm{g} / \mathrm{mL}$ concentration of epicatechin reduced TNF- $\alpha$ and IL-6 mRNA levels, having a higher effect on IL- $1 \alpha$ mRNA expression, and one which was very close to basal levels. A $25 \mu \mathrm{g} / \mathrm{mL}$ concentration of cocoa extract produced a greater downregulation of TNF- $\alpha$, IL- $1 \alpha$, and IL- 6 mRNA. Following cocoa extract treatment, IL- $1 \alpha$ mRNA remained at basal levels and LPS-induced TNF- $\alpha$ mRNA overexpression was reduced. In addition, the extract decreased NO secretion in a dose-dependent manner and with a greater effect than that produced by epicatechin.

There is experimental and clinical evidence that polyphenols from cocoa may reduce the production of more specific proinflammatory cytokines than those listed above, such as IL- $1 \beta$ and IL-2, while stimulating the production of antiinflammatory cytokines such as TGF- $\beta$ and IL-4. Selmi et al. [25] reviewed the studies carried out in resting or phytohemagglutinin A (PHA)-stimulated PBMCs. As they recall, IL-2 production is inhibited by pentamers to heptamers in PHA-stimulated PBMCs at mRNA level. In the case of IL- $1 \beta$, they describe the biphasic effect of flavonol fractions from monomers to tetramers, which suppressed its mRNA expression and protein secretion, while fractions from pentamers to decamers stimulated IL- $1 \beta$ production. Similar effects were observed in the case of TNF- $\alpha$, which was increased 4 -fold by decameric fractions, while monomer and dimer fractions increased TNF- $\alpha$ production only slightly. In the case of the anti-inflammatory cytokine IL-4, large cocoa flavanols fractions (pentamer through decamer) enhance protein levels from resting PBMCs, whereas the monomers to tetramers were not stimulatory. However, in PHA-stimulated cells, the monomer was the only flavanol fraction able to induce IL-4.

\subsection{Effects on Nuclear Factor Activation and Signal Transcrip-} tion. The regulatory effects of cocoa flavanols on nuclear factor- $\kappa \mathrm{B}$ (NF- $\kappa \mathrm{B})$ activation have also been studied. (-)epicatechin, $(+)$-catechin, and their dimeric forms were found to inhibit the NF- $\kappa \mathrm{B}$ activation induced by $12-\mathrm{O}-$ tetradecanoylphorbol-13-acetate (TPA) in T cells, with a clear reduction of NF- $\kappa$ B-DNA binding activity that leads to a reduction in IL-2 production. These effects were related to direct interaction with the inhibitor of $\kappa \mathrm{B}(\mathrm{I} \kappa \mathrm{B})$ to prevent its phosphorylation, thereby preventing NF- $\kappa B$ activation [25]. In a complementary study, Zhang et al. [75] investigated the effects of procyanidin dimer B2 on COX-2 expression and demonstrated that pretreatment for $30 \mathrm{~min}$ of differentiated human monocytic cells (THP-1) in culture with procyanidin $\mathrm{B} 2(50 \mu \mathrm{M})$ reduced the LPS-induced expression of this enzyme. This effect was correlated to the decreased activation of ERK, Jun-terminal kinase (JNK), and p38 mitogen-activated protein kinase (MAPK), as well as to the suppression of NF- $\kappa \mathrm{B}$ activation through stabilization of $\mathrm{I} \kappa \mathrm{B}$ proteins, which suggests that these signal-transducing enzymes could be potential targets for procyanidin B2.

8.3. Inflammatory Bowel Disease (IBD). Various studies conducted in both in vivo and in vitro models have provided evidence that pure polyphenols and natural polyphenol plant extracts can modulate intestinal inflammation. These studies indicate that pure polyphenols and plant polyphenolic extracts may play an anti-inflammatory role via the modulation of intracellular signaling cascades in intestinal cells. However, the number of studies on this subject is limited and the results have been contradictory [76].

Romier-Crouzet et al. [77] studied different polyphenol extracts, including those from cocoa, and tested their ability to modulate intestinal inflammation using human intestinal Caco- 2 cells treated for $4 \mathrm{~h}$ and stimulated with IL- $1 \beta$ for 24 or $48 \mathrm{~h}$. Surprisingly, they found that in the absence of any proinflammatory stimulus, the polyphenol extract of cocoa ( $50 \mu \mathrm{mol}$ of gallic acid/L) induced a basal $\mathrm{PGE}_{2}$ synthesis in Caco-2 cells. They attributed this effect to cyclooxygenase (COX)-1 induction. However, the same extract decreased $\mathrm{PGE}_{2}$ synthesis 4.6- and 2.2-fold in Caco-2 cells stimulated for 24 or $48 \mathrm{~h}$, respectively. As COX-1 seems to be implicated in maintaining mucosal integrity, the induction of COX1 activity could be a new beneficial property of cocoa polyphenol extract. 
A recent study performed by Andújar et al. [27] demonstrated the anti-inflammatory effects of a cocoa polyphenolenriched extract $(500 \mathrm{mg} / \mathrm{kg})$ on an experimental model of IBD. The extract was shown to reduce weight loss, improve normal stool consistency, and reduce or eliminate visible blood in feces in a dextran sulfate sodium (DSS)-induced model of colitis. In parallel, it reduced neutrophil infiltration, NO production, COX-2 expression, and expression of the signal transducers and activators of transcription (STAT)-3 and STAT $1 \alpha$ phosphorylation; however, the authors could not demonstrate a clear inhibitory effect on NF- $\kappa \mathrm{B}$ in the nuclear extract of the mid and distal colon. The activation of STAT1 triggers an important signaling pathway for many cytokine and growth factor receptors. STAT1 plays a relevant role in IBD and especially in ulcerative colitis, because there is an increased expression and activation of this transcription factor in the neutrophils and monocytes present in the intestinal lamina propria. In addition, STAT3 can be activated by different mediators and after dimerization and migration to the nucleus; it can induce the activation of various genes, with the consequent induction of other proinflammatory mediators. The inhibition of these transcription factors decreases the production of COX-2, IL$6, \mathrm{IL}-1 \beta$, and TNF- $\alpha$, which may explain the effect of cocoa polyphenol on experimental models of ulcerative colitis. In isolated peritoneal macrophages, the authors observed reductions in the proinflammatory cytokines IL- $1 \beta$, IL-6, and TNF- $\alpha$, probably as a consequence of the inhibition of the transcriptional factors STAT3 and STAT $1 \alpha$. However, interferon (IFN)- $\gamma$ was not modified. Finally, working with LPS-stimulated RAW 264.7 cells, a reduction of nuclear p65 was observed in the NF- $\kappa \mathrm{B}$ reporter gene assay.

The controversy on the effects of cocoa consumption was clarified somewhat by Vázquez-Agell et al. [78], who demonstrated that cocoa polyphenols reduce NF- $\kappa$ B activation in peripheral blood mononuclear cells in humans. They evaluated the effects of $40 \mathrm{~g}$ of cocoa powder with either milk or water against those of milk alone in 18 healthy volunteers. $\mathrm{NF}-\kappa \mathrm{B}$ activation in leukocytes and adhesion molecules was measured before and $6 \mathrm{~h}$ after each intervention. The results established that consumption of cocoa with water significantly decreased NF- $\kappa \mathrm{B}$ activation from the baseline value. Cocoa with milk produced no change, and milk alone led to a significant increase in NF- $\kappa \mathrm{B}$ activation. The concentration of soluble intercellular adhesion molecule (sICAM)-1 significantly decreased $6 \mathrm{~h}$ after cocoa-water and cocoa-milk interventions, with E-selectin decreasing only after cocoawater intervention. No significant changes were observed in the concentration of soluble vascular cell adhesion molecule (sVCAM)-1. The authors concluded that cocoa consumption may confer beneficial anti-inflammatory effects mediated by inhibition of the NF- $\kappa \mathrm{B}$-dependent transcription pathway or by direct interaction with certain cytokines and that the food matrix probably plays a crucial role in the modulation of this effect.

Ingestion or systemic administration of polyphenols may inhibit gene expression and induce phase II antioxidant and detoxifying proteins, which may help them prevent and/or ameliorate inflammatory colitis. Because enteral nutrition plays an important role in the management of IBD, artificial nutrition attempts to safely administer the essential and otherwise beneficial constituents of food to patients with an impaired ability to ingest or digest food; yet polyphenols are not included in the formulae. The addition of these compounds to artificial nutritional formulae could improve the outcome of patients with IBD in need of enteral nutrition [79].

\section{Phenolics from Cocoa in Cancer Prevention}

The antioxidant properties of cocoa or cocoa-derived products enriched in flavonoids may help protect against diseases in which oxidative stress is implicated as a causal or contributing factor. The most relevant antioxidant properties have been described above; the following sections are a compilation of these effects and their implications for cancer.

9.1. Cell Protection against Active Oxygen Radicals. Cocoa liquor polyphenols could thus be therapeutically beneficial, as they effectively inhibit mitomycin C-induced DNA damage and exert anticlastogenic effects. Because oxidative DNA damage seems to be implicated in mutagenesis and carcinogenesis, the anticlastogenic activities of cocoa extract, both through the inhibitory effect of cocoa polyphenols on the DNA strand cleavage induced by mitomycin $\mathrm{C}$ in vitro and through their effect against the formation of micronuclei induced by mitomycin $\mathrm{C}$ in bone marrow cells and peripheral blood cells of mice, may explain cocoa's role in the prevention of DNA damage, which probably occurs through the scavenging of active oxygen radicals generated in reactions initiated by mitomycin $C$ [80].

Cho et al. [81] studied the protective effects of a cocoa procyanidin fraction and procyanidin $\mathrm{B} 2$ against the apoptosis of PC12 rat pheochromocytoma cells induced by hydrogen peroxide. In this case, the fraction ( 1 and $5 \mu \mathrm{g} / \mathrm{mL}$ ) and procyanidin B2 $(1$ and $5 \mu \mathrm{M})$ reduced cell death by attenuating the hydrogen peroxide-induced fragmentation of the nucleus and DNA in PC12 cells. Hydrogen peroxide acts in part by inducing cleavage of poly(ADP-ribose)polymerase (PARP) and downregulating Bcl-XL and Bcl-2 in PC12 cells, but pretreatment with cocoa procyanidin fraction or procyanidin $\mathrm{B} 2$ before hydrogen peroxide treatment diminished PARP cleavage, increased Bcl-XL and Bcl-2 expression, and also inhibited activation of caspase- 3 by hydrogen peroxide while attenuating the phosphorylation of JNK and MAPK. Cocoa procyanidin fraction and procyanidin B2 thus have protective effects against both hydrogen peroxide and the oxidative stress induced by ROS, which has been strongly associated with the pathogenesis of neurodegenerative disorders, including Alzheimer's disease. A cocoa-rich diet also exerts antiproliferative effects in azoxymethane-induced colon cancer, decreasing ERK, protein kinase B (Akt), and cyclin D1 levels, as demonstrated in Wistar rats. In addition, it has proapoptotic effects, as evidenced by reduced Bcl-XL levels and increased levels of Bax and caspase-3 activity [82].

Martín et al. [83] studied the potential protective effect of a polyphenolic extract from cocoa on cell viability and 
the antioxidant defenses of cultured human HepG2 cells subjected to oxidative stress by $t$-butyl hydroperoxide. Pretreatment of cells with $0.05-50 \mu \mathrm{g} / \mathrm{mL}$ of cocoa polyphenol extract for 2 or $20 \mathrm{~h}$ completely prevented cell damage and enhanced the activity of antioxidant enzymes. Moreover, the lower levels of GSH caused by $t$-butyl hydroperoxide in HepG2 cells were partly recovered through pretreatment with cocoa-enriched extract, which also prevented in a dose-dependent fashion the increase in ROS induced by $t$ butyl hydroperoxide. Cocoa polyphenols thus seem to confer significant protection against oxidation in these cells.

Cocoa polyphenol extracts dose-dependently (10$100 \mu \mathrm{M})$ attenuated hydrogen peroxide-induced inhibition of gap-junction intercellular communication (GJIC) in rat liver epithelial (RLE) cells and inhibited the hydrogen peroxide-induced phosphorylation and internalization of connexin 43, which is a regulating protein of GJIC in RLE cells. It also inhibited hydrogen peroxide-induced accumulation of ROS and activation of ERK. However, cocoa polyphenol extract did not block hydrogen peroxideinduced phosphorylation of MAPK. Similar results were observed ex vivo in RLE cell lysates in which cocoa polyphenol extract inhibited hydrogen peroxide-induced MAPK/MEK1 activity. In these assays cocoa polyphenol bound directly with MEK1 to inhibit its activity. Inhibition of GJIC is strongly involved in carcinogenesis, particularly the tumor promotion process. Abnormal GJIC is attributable to phosphorylation of connexin 43 , which is a major protein constituting gap-junction channels. The activation of ERK and MAPK signaling pathways is strongly related to both the phosphorylation of connexin 43 and the inhibition of GJIC in RLE cells. The authors thus concluded that cocoa polyphenols protect against hydrogen peroxide-induced inhibition of GJIC through antioxidant activity and direct inhibition of MEK activity, which may contribute to their chemopreventive potential [84].

9.2. Antiproliferative Effects. Treatment of cells with $50 \mu \mathrm{g} /$ $\mathrm{mL}$ of procyanidin-enriched extracts inhibited cell growth by $70 \%$, blocking the cell cycle in the $\mathrm{G}_{2} / \mathrm{M}$ phase. The extracts also caused a significant decrease in the activities of ornithine decarboxylase and S-adenosylmethionine decarboxylase, two key enzymes of polyamine biosynthesis, thus leading to a decrease in the intracellular pool of polyamines. This could prove to be an important target in the antiproliferative effects of cocoa polyphenols [85].

9.3. Antimutagenic and Chemoprotective Effects. Ohno et al. [86] found that cocoa extracts have an antimutagenic effect on chemical mutagens (benzo[a]pyrene) that require metabolic activation by cytochrome P450 (CYP), specifically CYP1A, in vitro. Cocoa products may thus prevent initiation of cancer by inhibiting the metabolic activation of carcinogens by CYP1A. The authors used the Ames test to study the effects of various enriched extracts of whole cocoa products on the mutagenicity of benzo[a]pyrene in Salmonella typhimurium strain TA 98 and $t$-butyl hydroperoxide in S. typhimurium strain TA 102. Benzo[a]pyrene induces mutagenicity through metabolic activation, whereas $t$-butyl hydroperoxide induces it through generation of free radicals. While white chocolate did not modulate the number of revertant colonies produced by benzo[a]pyrene treatment, milk chocolate and cocoa powder extracts did. Surprisingly, none of the cocoa products tested affected the number of revertant colonies produced by $t$-butyl hydroperoxide. Nevertheless, at maximum concentration ( $13.25 \mathrm{mg}$ cocoa powder $/ \mathrm{mL}$ ), the crude cocoa powder extract reduced ethoxyresorufin $O$ deethylase activity to $17.4 \%$, suggesting that whole cocoa products inhibit CYP1A activity, which may prevent DNA damage by reducing the metabolic activation of carcinogens.

In another study, Oleaga et al. [87] evaluated the effect of polyphenol cocoa extract in breast cancer cells (MCF-7 and SKBR3). After incubation with $250 \mathrm{ng} / \mu \mathrm{L}$ of cocoa extract, 7 genes out of 84 were overexpressed and 1 was underexpressed in MCF-7 cells, whereas 9 genes were overexpressed in SKBR3 cells. Because CYP1A1 was expressed in both cell lines, it was selected for further study. CYP1A1 mRNA, protein levels, and enzymatic activity all increased upon incubation with polyphenol cocoa extract. The combination of polyphenol cocoa extract with tamoxifen caused a synergistic cytotoxicity in both cell lines due to increased apoptosis of MCF-7 cells. The authors concluded that the interaction between estrogen receptor (ER)- $\alpha$ and aryl hydrocarbon receptor (AhR) upon incubation with polyphenol cocoa extract leads to the induction of CYP1A1 in breast cancer cells. The synergy observed between polyphenol cocoa extract and noncytotoxic tamoxifen concentrations opens the possibility for a combination therapy in which polyphenols from cocoa are used to boost the efficacy of tamoxifen.

A cocoa procyanidin fraction and procyanidin B2 at $5 \mu \mathrm{g} / \mathrm{mL}$ and $40 \mu \mathrm{M}$, respectively, inhibited TPA-induced neoplastic cell transformation of $\left(\mathrm{JB} 6 \mathrm{P}^{+}\right)$mouse epidermal $\left(J B 6 \mathrm{P}^{+}\right)$cells by 47 and 93\%, respectively, through the suppression of the kinase activity of MEK. They also inhibited the expression of COX-2, the TPA-induced activation of activator protein (AP)-1 and NF- $\kappa \mathrm{B}$, and the TPA-induced phosphorylation of MEK, ERK, and p90 ribosomal s6 kinase, all of which are implicated in inflammation and cancer [88].

Kim et al. [89] studied a cocoa polyphenol extract and its effect on vascular endothelial growth factor (VEGF) expression JB6 $\mathrm{P}^{+}$cells as well as its biological consequences, including its potential effects against proinflammatory cytokine-mediated skin cancer and inflammation. The cocoa polyphenol extract $(5-20 \mu \mathrm{g} / \mathrm{mL})$ inhibited TNF- $\alpha$ induced upregulation of VEGF by reducing TNF- $\alpha$-induced activation of the nuclear transcription factors AP-1 and NF$\kappa \mathrm{B}$, which are key regulators of VEGF expression. The extract also inhibited TNF- $\alpha$-induced phosphorylation of Akt and ERK, blocked activation of their downstream kinases (p70 ribosomal protein S6 kinase and p90 ribosomal protein S6 kinase), and suppressed phosphoinositide 3-kinase (PI3 K) activity by binding PI3 $\mathrm{K}$ directly. Moreover, although it did not affect the TNF- $\alpha$-induced phosphorylation of MEK1, it suppressed TNF- $\alpha$-induced MEK1 activity. The direct inhibition of PI3 K and MEK1 activities though the reduction of TNF- $\alpha$-induced upregulation of VEGF may contribute to the chemopreventive potential of cocoa polyphenol. Indeed, the expression of VEGF, a multifunctional cytokine that is 
a key regulator of angiogenesis, is not only associated with tumorigenesis, but also with cardiovascular disease, rheumatoid arthritis, and psoriasis. Because cancerous cells require blood vessels to increase the flow of nutrients and oxygen vital for their development and survival via angiogenesis, the inhibition of VEGF expression may be a promising approach for protecting against carcinogenesis. Cocoa polyphenols could thus be considered potential chemopreventive agents against cancer and inflammation.

\section{Phenols from Cocoa in Tooth Health}

The production of caries and consumption of chocolate are often cited in the literature, with the intake of chocolate considered detrimental for tooth health. However, this negative effect is due to high concentrations of compounds present in chocolate other than cocoa, such as sugar. Ferrazzano et al. [90] were of the first to note the possible protective effect of cocoa on dental caries. Cocoa products contain inhibitors of the dextransucrase enzyme, which is responsible for the formation of the plaque extracellular polysaccharides from sucrose. Moreover, phenolic substances may be responsible for the observed anticaries effect of cocoa powder. Indeed, a water-soluble extract, of cocoa powder was shown to significantly reduce caries scores in rats infected with Streptococcus sobrinus, a potent cariogenic $\alpha$-haemolytic streptococcus. Complementary studies have demonstrated that cocoa polyphenols inhibit the growth of S. sanguinis, but not that of S. mutans. Although S. mutans appears to be refractory to the growth-inhibitory or lethal effects of the cocoa polyphenol pentamer in routine studies, the compound still managed to significantly inhibit acid production from sucrose. Indeed, a recent study reports on the use of the ground husk of cocoa beans, a by-product of cocoa manufacture, to prepare a mouth rinse for children that was even more effective in decreasing plaque scores.

Tomofuji et al. [91] studied the potential effects of a cocoa-enriched diet (10\% of the total food intake) on gingival oxidative stress in a rat-periodontitis model and concluded that a diet rich in cocoa could diminish periodontitis-induced oxidative stress, which, in turn, might suppress the progression of periodontitis. In fact, they observed that rats with induced-experimental periodontitis which were fed a cocoa-enriched diet did not show impairments in serum reactive oxygen metabolite levels or gingival levels for 8-hydroxydeoxyguanosine, nor did they exhibit a reduced/oxidized glutathione ratio, as did the control group. They proposed further studies to definitively establish the bacterial pathogens in the periodontium and the optimum dose of cocoa in the diet, along with new experiments to develop an inflammatory process equivalent to chronic periodontitis in humans.

Mao et al. [92] suggested that the consumption of some cocoas and chocolates could reduce the risk for dental caries and periodontal disease, justifying their hypothesis on the basis of purified cocoa flavanol oligomers' immunomodulatory effects on the in vitro production of cytokines IL-1 $\beta$, IL-2, IL-4, and IL-5. These authors established a biphasic-type effect in which the larger (hexamer through decamer) procyanidin fractions showed more activity in regulating cytokine production. In the case of IL-5, the smaller procyanidin fractions (monomer through trimer) can augment IL-5 secretion. This cytokine is implicated in the differentiation of $\mathrm{B}$ cells to IgA-producing plasma cells. IgA is considered to be protective in periodontal diseases; therefore in this enhanced effect of certain cocoa oligomer fractions could be therapeutic for periodontal disease.

\section{Other Pharmacological Effects}

11.1. Antiobesity Effects. Rats fed a cocoa-enriched diet experienced a reduction in body weight, most likely due to lower adipose tissue synthesis. Ferrazzano et al. hypothesized that the polyphenols contained in cocoa may have antiobesity effects due to their ability to suppress fatty acid synthesis while stimulating cell energy expenditure in the mitochondria [90].

Moreover, cocoa consumption may also have beneficial effects on satiety, cognitive function, and mood [93].

11.2. Chronic Fatigue Syndrome. Sathyapalan et al. [94] studied a polyphenol-rich chocolate and observed that it reduced the symptoms of chronic fatigue syndrome. In fact, in a double blind, randomized, clinical pilot crossover study with 10 subjects, the authors compared the effect of consuming either high cocoa liquor/polyphenol-rich chocolate or simulated isocalorific chocolate (cocoa liquor free/low polyphenol content) on fatigue and residual function in subjects with chronic fatigue syndrome. After 8 weeks, subjects in the high cocoa liquor/polyphenol-rich chocolate group showed significant improvement as measured by different scoring methods, including the Chalder Fatigue Scale and Hospital Anxiety and Depression scores, whereas subjects taking isocalorific chocolate deteriorated.

11.3. Neurodegenerative Diseases. Bisson et al. [95] studied and demonstrated that a cocoa polyphenol extract (Acticoa powder) may help delay age-related brain impairments, including cognitive deficits in normal ageing and perhaps neurodegenerative diseases. In experiments using rats, administration of Acticoa powder $(24 \mathrm{mg} / \mathrm{kg} / \mathrm{day}$, orally, between 15 and 27 months of age) did not show any influence on weight or food and water consumption throughout the study period; the benefits observed with the cocoa extract are thus not due to dietary restriction. While the results of this study suggest that Acticoa powder may be beneficial in retarding age-related brain impairments, further studies are needed to elucidate the mechanisms of cocoa polyphenols in neuroprotection and to explore their effects in man [95]. Moreover, cocoa consumption protects nerves from injury and inflammation [93].

11.4. Antimalarial Effects. Numerous anecdotal reports of reduced episodic malaria in people from Ghana who drink a natural, unsweetened cocoa beverage daily prompted a search for scientific mechanisms to account for cocoa's possible antimalarial effects. In a review of the data from 
TABLE 1: Effects of cocoa phenolics on metabolism, cardiovascular diseases, inflammation, and cancer prevention.

(a)

\section{Metabolic and endocrine disorders}

Assays

Effects

\begin{tabular}{|c|c|c|}
\hline & Assays & Effects \\
\hline \multirow[t]{2}{*}{ In vitro } & $\begin{array}{l}\text { Pancreatic } \alpha \text {-amylase, pancreatic lipase, and secreted } \\
\mathrm{PLA}_{2} \text { inhibitions }[45]\end{array}$ & $\begin{array}{l}\text { (i) Cocoa extracts and procyanidins dose-dependently } \\
\text { inhibited pancreatic } \alpha \text {-amylase, pancreatic lipase, and } \\
\text { secreted PLA } \mathrm{PL}_{2} \text {, showing greater inhibitory activity against } \\
\text { PLA }_{2} \text {. The inhibitory potency increases with the degree of } \\
\text { polymerization }\end{array}$ \\
\hline & HepG2 and Caco2 [50] & $\begin{array}{l}\text { (i) }(+) \text {-catechin, }(-) \text {-epicatechin, procyanidin } \mathrm{B} 2 \text {, } \\
\text { procyanidin } \mathrm{C} 1 \text {, and cinnamtannin } \mathrm{A} 2(10 \mu \mathrm{M}) \text { : } \\
\uparrow \text { ApoA } 1 \downarrow \text { ApoB due to upregulation of SREBPs and } \\
\text { increased LDL receptor activity }\end{array}$ \\
\hline
\end{tabular}

Randomized crossover trial with 19 hypertensive patients with impaired glucose tolerance [47]

Randomized, crossover feeding trial in 42 high-risk volunteers [51]

Meta-analysis of 8 randomized controlled trials

In vivo involving 215 participants [52]

Randomized, single-blind, crossover study with 14 overweight/obese subjects [53]

Randomized, placebo-controlled double-blind crossover trial [31] (i) Flavanol-rich dark chocolate (100 g/day for 15 days):

(a) $\downarrow$ insulin resistance, systolic and diastolic blood pressure, total cholesterol, and LDL-cholesterol

(b) $\uparrow$ insulin sensitivity, $\beta$-cell function, and flow-mediated dilation

(i) Chronic cocoa consumption ( $42 \mathrm{~g} /$ day for 4 weeks):

(a) significant increases of phase II metabolites

(glucuronide, sulfate conjugates) in $24 \mathrm{~h}$ urine

(b) $\uparrow$ HDL-cholesterol

(c) $\downarrow$ LDL-cholesterol

(i) Short-term cocoa consumption:

(a) $\downarrow$ LDL and total cholesterol (changes depended on the amount of cocoa consumed and the health status of participants)

(i) $20 \mathrm{~g}$ of dark chocolate with $500 \mathrm{mg}$ of polyphenols and then $20 \mathrm{~g}$ of dark chocolate with $1000 \mathrm{mg}$ of polyphenols or vice versa for 2 weeks separated by a 1-week washout period:

(a) both doses were equally effective in reducing fasting blood glucose levels, systolic blood pressure, and diastolic blood pressure

(i) High polyphenol chocolate (16.6 mg of epicatechins in $45 \mathrm{~g})$ :

(a) $\uparrow$ HDL-cholesterol

(b) $\downarrow$ LDL-cholesterol, total cholesterol/HDL ratio High-polyphenol chocolate is effective in improving the atherosclerotic cholesterol profile in patients with diabetes

(b)

Assays Effects

Forty-two high-risk patients in a randomized crossover feeding trial for 4 weeks [32]

(i) $40 \mathrm{~g}$ of cocoa powder with $500 \mathrm{~mL}$ skim milk/day:

(a) $\downarrow$ VLA-4, CD40, and CD36 in monocytes

(b) $\downarrow$ serum concentrations of P-selectin and ICAM- 1

(i) Individuals with low baseline levels of TGF- $\beta_{1}$ : TGF- $\beta_{1}$ release was enhanced in the range of $16-66 \%$. Low-molecular-weight fractions ( $\leq$ pentamers) were more effective than their larger counterparts (hexamer or higher), with the monomer and dimer inducing the greatest increases (66\% and 68\%, resp.)

(ii) Individuals with high baseline levels of TGF- $\beta_{1}$ : TGF- $\beta_{1}$ secretion was inhibited, being the inhibition most pronounced for trimmers through decamers $(28-42 \%$, resp.) and moderate for monomers to dimers (17-23\%, resp.)

(i) $2 \mathrm{~h}$ after dark chocolate intake ( $860 \mathrm{mg}$ of polyphenols, of which $58 \mathrm{mg}$ were epicatechin):

(a) detectable epicatechin levels were observed

(b) less DNA damage to mononuclear blood cells

(c) no effect on plasma total antioxidant activity

(ii) Effects were no longer evident after $22 \mathrm{~h}$ : dark chocolate 
(b) Continued.

\section{Cardiovascular diseases}

Assays

Blinded parallel-design study with 32 healthy subjects consuming $234 \mathrm{mg}$ cocoa phenolics a day for 28 days [63]

Double-blind, randomized study with 22 heart transplant recipients [64]
Effects

(i) $\uparrow$ Plasma epicatechin and catechin concentrations by $81 \%$ and $28 \%$, respectively

(ii) $\downarrow$ Platelet function

(i) $2 \mathrm{~h}$ after ingestion of $40 \mathrm{~g}$ of flavonoid-rich dark chocolate $(0.27 \mathrm{mg} / \mathrm{g}$ of catechin and $0.9 \mathrm{mg} / \mathrm{g}$ of epicatechin, with a total polyphenol content of $15.6 \mathrm{mg}$ of epicatechin equivalents per gram):

(a) $\uparrow$ coronary artery diameter

(b) improved endothelium-dependent coronary vasomotion

(c) $\downarrow$ platelet adhesion

(i) Smokers:

(a) $\uparrow$ platelet recruitment, platelet formation of ROS and eicosanoids, and NOX2 activation

(ii) Smokers + dark chocolate group:

(a) $\downarrow$ platelet ROS, $\mathrm{PGF}_{2 \alpha}$, and NOX2 activation decreased

Crossover, single blind study with 20 healthy subjects and 20 smokers who received $40 \mathrm{~g}$ of dark (cocoa $>85 \%$ ) or milk $($ cocoa $<35 \%)$ chocolate [65] significantly

(iii) Healthy + dark chocolate:

(a) platelet variables did not change

(iv) Milk chocolate (smokers and healthy):

(a) no changes detected in either of the groups treated with milk chocolate

Single oral administration of a natural flavonoid-enriched cocoa powder $(50-600 \mathrm{mg} / \mathrm{kg})$ in spontaneously hypertensive rats [67]

Antihypertensive effect in hypertensive rats without modifying the arterial blood pressure in normotensive rats. No dose-response effect was observed

(i) Polyphenol-treated group:

(a) $\downarrow$ area of atherosclerotic lesions in the aortas of the

Fifty male Kurosawa and Kusanagi-hypercholesterolemic rabbits received $100 \mathrm{~g} /$ day of standard diet or cacao liquor polyphenol diet [68] polyphenol-treated group was significantly smaller than in the control group

(b) preserved parasympathetic nervous tone

(c) no differences in the plasma lipid concentrations

Six-month clinical trial with 36 prehypertensive healthy adult volunteers, at content levels of 120-139 and 80-89 $\mathrm{mmHg}$ [70]

(i) $50 \mathrm{~g}$ of dark chocolate/day:

(a) no significant differences were observed in the blood pressures of the treated and control groups

(i) Significantly inhibited the angiotensin I converting enzyme activity

In vitro measurement of the kinetics of inhibition of purified angiotensin I converting enzyme from rabbit lung [72]

(ii) Monomeric flavan-3-ols: $\mathrm{IC}_{50}$ in the $\mathrm{mM}$ range

(iii) Dimer and trimer: $\mathrm{IC}_{50}$ in the $100 \mu \mathrm{M}$ range

(iv) Larger procyanidins: $\mathrm{IC}_{50}$ in the $10 \mu \mathrm{M}$ range (c)

\section{Anti-inflammatory properties}

In vitro assays

Polyphenol

Effect

(i) Monomers-pentamers: $\uparrow$ of LPS-induced synthesis of IL- $1 \beta$, IL- 6 , IL-10, and TNF- $\alpha$

Unstimulated and

LPS-stimulated PBMCs [20]

Different flavanol fractions $(20 \mu \mathrm{g} / \mathrm{mL})$

(ii) Long- and short-chain flavanol fractions: $\uparrow$ the production of GM-CSF in the absence of LPS and the expression of CD69 and CD83

(i) $\downarrow$ MCP- 1 and TNF- $\alpha$ at the transcriptional

(i) Epicatechin $(58 \mu \mathrm{g} / \mathrm{mL})$

Macrophages [73]

(ii) Cocoa extract $(50 \mu \mathrm{g} / \mathrm{mL})$

(iii) Isoquercitrin $(18.6 \mu \mathrm{g} / \mathrm{mL})$ level

(ii) $\downarrow$ TNF- $\alpha$, IL- $1 \alpha$, and IL-6 mRNA levels

(iii) $\downarrow$ NO secretion

(i) $\downarrow$ Expression of COX-2

THP-1 [72]

Procyanidin dimer B2: pretreatment for

(ii) $\downarrow$ Activation of ERK, JNK, and p38 MAPK

(iii) Suppresses NF- $\kappa$ B activation through stabilization of $\mathrm{I} \kappa \mathrm{B}$ proteins

(i) In the absence of proinflammatory stimuli, the polyphenol extract of cocoa induces a basal $\mathrm{PGE}_{2}$ synthesis due to COX-1 induction

Caco-2 IL-1 $\beta$-stimulated [77]

Polyphenol extract of cocoa $(50 \mu \mathrm{mol}$ of gallic acid/L); 4 h treatment (ii) After 24 or 48 h stimulation: it decreased

$\mathrm{PGE}_{2}$ synthesis 4.6- and 2.2-fold, respectively 
(c) Continued.

Anti-inflammatory properties

In vivo/Exvivo

DSS-induced ulcerative colitis in Balb/C mice [27]

Cocoa polyphenol-enriched extract $(500 \mathrm{mg} / \mathrm{kg})$
Effect

(i) In vivo: $\downarrow$ weight loss, improves normal stool consistency, $\downarrow$ visible blood in feces, $\downarrow$ neutrophil infiltration, $\downarrow$ NO production, $\downarrow$ COX- 2

expression, $\downarrow$ STAT3 and STAT $1 \alpha$ phosphorylation

(ii) Ex vivo in peritoneal macrophages: $\downarrow$ IL-6,

IL- $1 \beta$, and TNF- $\alpha$

(iii) In vitro in LPS-stimulated RAW 264.7 cells: inhibits NF- $\kappa \mathrm{B}$

(i) Cocoa + water:

(a) $\downarrow$ NF- $\kappa$ B activation in leukocytes and adhesion molecules
(b) $\downarrow$ sICAM- 1

(c) $\downarrow$ E-selectin

(ii) Cocoa + milk:

(a) no change in NF- $\kappa$ B activation

(b) $\downarrow$ sICAM- 1

(iii) Milk:

(a) $\uparrow$ NF- $\kappa$ B activation
Human PBMCs
volunteers [78] water (i) After incubation with $250 \mathrm{ng} / \mu \mathrm{L}$ of cocoa extract, 7 genes out of 84 were overexpressed and 1 was underexpressed in MCF-7 cells, whereas 9 genes were overexpressed in SKBR3 cells

MCF-7 and SKBR3 [87] $\quad$ (ii) CYP1A1 mRNA, protein levels, and enzymatic activity increased

(iii) The combination of polyphenol cocoa extract + tamoxifen caused a synergistic cytotoxicity

(i) Cocoa polyphenol extracts dose-dependently $(10-100 \mu \mathrm{M})$ attenuated in vitro hydrogen peroxide-induced

(a) inhibition of GJIC

RLE cells in vitro and ex vivo [84] $\quad$ (b) phosphorylation and internalization of connexin 43

(c) accumulation of ROS and activation of ERK

(ii) Ex vivo in RLE cell lysates

(a) inhibits hydrogen peroxide-induced MAPK/ MEK1 activity

\begin{tabular}{|c|c|}
\hline \multicolumn{2}{|r|}{ In vivo } \\
\hline Animals & Effects \\
\hline $\begin{array}{l}\text { Wistar Han rats ( } 5 \text { weeks old) } \\
\text { pretreated for } 2 \text { weeks with a } \\
\text { cocoa-rich diet and injected with } \\
\text { azoxymethane once a week for } 2 \\
\text { weeks [82] }\end{array}$ & $\begin{array}{l}\text { (i) The cocoa-rich diet ( } 1 \mathrm{~g} \text { of polyphenol/kg of diet): } \\
\text { (a) antiproliferative effects in azoxymethane-induced colon cancer: } \downarrow \text { ERK, Akt, and } \\
\text { cyclin D1 } \\
\text { (b) proapoptotic effects: } \downarrow \text { Bcl-X } \mathrm{X}_{\mathrm{L}} \text { levels and } \uparrow \text { levels of Bax and caspase-3 activity }\end{array}$ \\
\hline & (d) \\
\hline \multicolumn{2}{|r|}{$\begin{array}{c}\text { Cancer prevention } \\
\text { In vitro }\end{array}$} \\
\hline Cell line & ffects \\
\hline
\end{tabular}

(i) Treatment of cells with $50 \mu \mathrm{g} / \mathrm{mL}$ of procyanidin-enriched extracts:

Caco-2 cells [85]

(a) inhibits cell growth by $70 \%$, blocking the cell cycle in the $\mathrm{G}_{2} / \mathrm{M}$ phase

(b) $\downarrow$ activities of ornithine decarboxylase and S-adenosylmethionine decarboxylase, and therefore, $\downarrow$ the intracellular pool of polyamines

(i) Cocoa procyanidin fraction (1 and $5 \mu \mathrm{g} / \mathrm{mL}$ ) and procyanidin $\mathrm{B} 2(1$ and $5 \mu \mathrm{M})$ :

PC12 rat pheochromocytoma cells [81]

(a) $\downarrow$ cell death attenuating the hydrogen peroxide-induced fragmentation of the nucleus and DNA

(b) $\downarrow$ PARP cleavage, increased Bcl- $\mathrm{X}_{\mathrm{L}}$ and Bcl-2 expression, and also inhibited activation of caspase- 3 by hydrogen peroxide while attenuating the phosphorylation of JNK and MAPK

(i) Pretreatment of cells subjected to oxidative stress with $0.05-50 \mu \mathrm{g} / \mathrm{mL}$ of cocoa polyphenol extract for 2 or $20 \mathrm{~h}$ :

HepG2 cells [83] (a) completely prevented cell damage and enhanced the activity of antioxidant enzymes

(b) recovered levels of GSH

(c) prevented in a dose-dependent fashion the increase in ROS 
(d) Continued.

Cancer prevention

In vitro

(i) Treatment with benzo[a]pyrene

(a) white chocolate did not modulate the number of revertant colonies produced by treatment

(b) milk chocolate and cocoa powder extracts did

Salmonella typhimurium strain TA 98 and TA 102 [86]

(ii) Treatment with $t$-butyl hydroperoxide

(a) none of the cocoa products tested affected the number of revertant colonies

(b) $13.25 \mathrm{mg}$ cocoa powder/mL reduced ethoxyresorufin $O$-deethylase activity to $17.4 \%$ suggesting that whole cocoa products inhibit CYP1A activity

(i) Cocoa procyanidin fraction $(5 \mu \mathrm{g} / \mathrm{mL})$ and procyanidin $\mathrm{B} 2(40 \mu \mathrm{M})$ inhibit

(a) TPA-induced neoplastic cell transformation at 47 and $93 \%$, respectively

(b) phosphorylation of MEK, ERK, and p90 ribosomal s6 kinase

(c) COX-2 expression

(d) AP- 1 and NF- $\kappa$ B activation, and the TPA induced

JB6 P+ cells $[88,89]$

(ii) Cocoa polyphenol extract $(5-20 \mu \mathrm{g} / \mathrm{mL})$

(a) inhibits TNF- $\alpha$-induced upregulation of VEGF by reducing TNF- $\alpha$-induced activation of AP- 1 and NF- $\kappa \mathrm{B}$

(b) inhibits TNF- $\alpha$-induced phosphorylation of Akt and ERK

(c) suppresses PI3K activity by binding PI3K directly

(d) suppresses TNF- $\alpha$-induced MEK1 activity

(i) After incubation with $250 \mathrm{ng} / \mu \mathrm{L}$ of cocoa extract, 7 genes out of 84 were overexpressed and 1 was underexpressed in MCF-7 cells, whereas 9 genes were overexpressed in SKBR3 cells

(ii) CYP1A1 mRNA, protein levels, and enzymatic activity increased

(iii) The combination of polyphenol cocoa extract + tamoxifen caused a synergistic cytotoxicity

(i) Cocoa polyphenol extracts dose-dependently $(10-100 \mu \mathrm{M})$ attenuated in vitro hydrogen peroxide-induced

(a) inhibition of GIC

RLE cells in vitro and ex vivo [84] $\quad$ (b) phosphorylation and internalization of connexin 43

(c) accumulation of ROS and activation of ERK

(ii) Ex vivo in RLE cell lysates

(a) inhibits hydrogen peroxide-induced MAPK/MEK1 activity

In vivo

Animals pretreated for 2 weeks with a cocoa-rich diet and injected with azoxymethane once a week for 2 weeks [82]

\section{Effects}

(i) The cocoa-rich diet ( $1 \mathrm{~g}$ of polyphenol/kg of diet):

(a) antiproliferative effects in azoxymethane-induced colon cancer: $\downarrow$ ERK, Akt, and cyclin D1

(b) proapoptotic effects: $\downarrow \mathrm{Bcl}-\mathrm{X}_{\mathrm{L}}$ levels and $\uparrow$ levels of Bax and caspase- 3 activity

the literature on this subject, Addai [96] established five possible antimalarial mechanisms for cocoa. Thus, the effects could be due to the increased availability of antioxidants in plasma, membrane effects in general and in the erythrocyte membrane in particular, increased plasma levels of NO, specific antimalarial activity of cocoa flavanoids and their derivatives, and enhancement of the immune system mediated by components of cocoa including cocoa polyphenols.

11.5. Effects on Skin Tone and Elasticity. Cocoa polyphenols have a positive effect on skin structure when applied for at least 5 days. Studying these effects ex vivo, Gasser et al. [97] observed that cocoa polyphenols exhibit a positive action on the parameters assessed, including glycosaminoglycans and collagens I, III, and IV, associated with skin tone and elasticity. The doses at which they improve each of these parameters were determined to be $0.75 \%$ and $0.50 \%$.

Mukai et al. [98] studied the suppression by a cocoa polyphenol extract $(100 \mathrm{mg} / \mathrm{kg}$, orally) of aryl hydrocarbon receptor transformation in C57BL/6 mice. Three hours after administration of the aryl hydrocarbon receptor agonist 3-methylcholanthrene $(10 \mathrm{mg} / \mathrm{kg}$, i.p.), the cocoa extract suppressed the induced transformation to control levels by inhibiting the formation of a heterodimer between the aryl hydrocarbon receptor and an aryl hydrocarbon receptor nuclear translocator in the liver. The extract also suppressed 3-methylcholanthrene-induced CYP1A1 expression and $\mathrm{NAD}(\mathrm{P}) \mathrm{H}$ : quinone-oxidoreductase activity while increasing glutathione $S$-transferase activity after $25 \mathrm{~h}$. The authors concluded that the intake of cocoa polyphenol extract suppresses the toxicological effects of dioxins in the body [98]. Moreover, in topical preparations, protect the skin from oxidative damage caused by ultraviolet (UV) radiation [93].

\section{Conclusions}

Dark chocolate and cocoa enriched-polyphenol extracts may be beneficial for human health in different ways. Cocoa 
polyphenols have antioxidant properties, which endow them with various positive effects against several pathological disorders, including cardiovascular disease, inflammatory processes, and cancer. Indeed, cocoa polyphenols induce coronary vasodilatation, increase endothelial NO concentrations to induce vascular relaxation, improve vascular function, and decrease platelet adhesion. Moreover, they decrease levels of LDL-cholesterol and its oxidation while increasing HDL-cholesterol. Polyphenols also have antiinflammatory activity, especially against IBD, through the inhibition of different transcription factor and cytokines. These effects also produce chemopreventive effects on other chronic diseases such as cancer by inhibiting the growth of various cancer cell lines. Of special interest are the effects of polyphenols on colon cancer. Indeed, the protective effects of polyphenols against IBD prevent it from evolving into cancer. In addition, it has been demonstrated that polyphenols cause nonapoptotic cell death, blocking the cell cycle in the $\mathrm{G}_{2} / \mathrm{M}$ phase, which potentiates their antiproliferative effects. To summarize these effects, Table 1 lists the most relevant studies on cocoa phenolics and their findings, including the principal effects on metabolism, cardiovascular diseases, inflammation, and cancer prevention.

\section{Abbreviations, Symbols, and Cell Lines}

$\begin{array}{ll}\text { ABTS: } & \text { 2,2'-Azino-bis(3-ethylbenzthiazoline-6- } \\ & \text { sulphonic acid) } \\ \text { Akt: } & \text { Protein kinase B } \\ \text { AhR: } & \text { Aryl hydrocarbon receptor } \\ \text { AP: } & \text { Activator protein } \\ \text { Apo: } & \text { Apolipoprotein } \\ \text { Caco-2: } & \text { Human epithelial colorectal adenocar- } \\ & \text { cinoma cells } \\ \text { CD: } & \text { Cluster of differentiation } \\ \text { CD36: } & \text { Thrombospondin receptor } \\ \text { CD40: } & \text { TNF receptor superfamily member } 5 \\ \text { cGMP: } & \text { Cyclic guanosine monophosphate } \\ \text { COX: } & \text { Cyclooxygenase } \\ \text { CYP: } & \text { Cytochrome P450 } \\ \text { DNA: } & \text { Deoxyribonucleic acid } \\ \text { DPPH: } & \text { 2,2-Diphenyl-1-pycrylhydrazyl } \\ \text { DSS: } & \text { Dextran sulfate sodium } \\ \text { EDHF: } & \text { Endothelium-derived hyperpolarizing factor } \\ \text { eNOS: } & \text { Endothelial nitric oxide synthase } \\ \text { ER- } \alpha: & \text { Estrogen receptor- } \alpha \\ \text { ERK: } & \text { Extracellular signal-regulated protein kinase } \\ \text { FRAP: } & \text { Ferric reducing-antioxidant power } \\ \text { GJIC: } & \text { Gap-junction intercellular communication } \\ \text { GM-CSF: } & \text { Granulocyte macrophage colony-stimulating } \\ & \text { factor } \\ \text { HDL: } & \text { High-density lipoprotein } \\ \text { HepG2: } & \text { Human hepatocellular carcinoma } \\ \text { IBD: } & \text { Inflammatory bowel disease } \\ \text { IC } 50: & \text { Inhibitory concentration-50 } \\ \text { ICAM: } & \text { Intercellular adhesion molecule } \\ \text { IFN- } \gamma: & \text { Interferon- } \gamma \\ \text { Ig: } & \text { Immunoglobulin } \\ & \\ & \end{array}$

I $\kappa \mathrm{B}: \quad$ Inhibitor of $\kappa \mathrm{B}$

IL: Interleukin

i.p.: Intraperitoneally

JNK: Jun-terminal kinase

LDL: Low-density lipoprotein

LOX: Lipoxygenase

LPS: Lipopolysaccharide

LT: Leukotrienes

MAPK: Mitogen-activated protein kinase

MCF-7: Breast cancer cells (Michigan Cancer Foundation-7)

MCP: Monocyte chemoattractant protein

MEK: Mitogen-activated protein kinase kinase

MMP: Matrix metalloproteinase

MPO: Myeloperoxidase

MT1: Membrane type-1

NADPH: Nicotinamide adenine dinucleotide phosphate

NF- $\kappa \mathrm{B}: \quad$ Nuclear factor $-\kappa \mathrm{B}$

NO: $\quad$ Nitric oxide

NOX: NADPH oxidase

PARP: Poly(ADP-ribose)polymerase

PBMCs: Human peripheral blood mononuclear cells

PC12: Rat pheochromocytoma cells

PG: $\quad$ Prostaglandin

PHA: Phytohemagglutinin

PI3 K: Phosphoinositide 3-kinase

$\mathrm{PLA}_{2}$ : $\quad$ Phospholipase $\mathrm{A}_{2}$

RNA: Ribonucleic acid

ROS: $\quad$ Reactive oxygen species

RLE: Rat liver epithelial

sICAM: Soluble intercellular adhesion molecule; CD54

SKBR3: Human breast carcinoma cells

SREBP: Sterol regulatory element binding protein

STAT: $\quad$ Signal transducers and activators of transcription

sVCAM: Soluble vascular cell adhesion molecule; CD106

TGF- $\beta_{1}$ : Transforming growth factor- $\beta_{1}$

THP-1: Human monocytic cells

TNF- $\alpha$ : Tumor necrosis factor- $\alpha$

TPA: 12-O-Tetradecanoylphorbol-13-acetate

UV: Ultraviolet

VEGF: Vascular endothelial growth factor

VLA-4: Very late antigen-4

VSMC: Vascular smooth muscle cell.

\section{Acknowledgments}

The authors thank the Spanish Government (MICIIN and FEDER, Grant SAF2009-10059-C03-01) for financial support. I. Andújar is grateful for a fellowship from the Generalitat Valenciana (Grant BFPI/2008/040).

\section{References}

[1] K. Szkudelska, L. Nogowski, and T. Szkudelski, "Resveratrol, a naturally occurring diphenolic compound, affects lipogenesis, 
lipolysis and the antilipolytic action of insulin in isolated rat adipocytes," The Journal of Steroid Biochemistry and Molecular Biology, vol. 113, no. 1-2, pp. 17-24, 2009.

[2] J. Ahn, I. Cho, S. Kim, D. Kwon, and T. Ha, "Dietary resveratrol alters lipid metabolism-related gene expression of mice on an atherogenic diet," Journal of Hepatology, vol. 49, no. 6, pp. 1019-1028, 2008.

[3] C. Li, A. Allen, J. Kwagh et al., "Green tea polyphenols modulate insulin secretion by inhibiting glutamate dehydrogenase," The Journal of Biological Chemistry, vol. 281, no. 15, pp. 10214-10221, 2006.

[4] M. Bose, J. D. Lambert, J. Ju, K. R. Reuhl, S. A. Shapses, and C. S. Yang, "The major green tea polyphenol, (-)epigallocatechin-3-gallate, inhibits obesity, metabolic syndrome, and fatty liver disease in high-fat-fed mice," The Journal of Nutrition, vol. 138, no. 9, pp. 1677-1683, 2008.

[5] M. A. Potenza, F. L. Marasciulo, M. Tarquinio et al., "EGCG, a green tea polyphenol, improves endothelial function and insulin sensitivity, reduces blood pressure, and protects against myocardial I/R injury in SHR," American Journal of Physiology, vol. 292, no. 5, pp. E1378-E1387, 2007.

[6] A. Ejaz, D. Wu, P. Kwan, and M. Meydani, "Curcumin inhibits adipogenesis in 3T3-L1 adipocytes and angiogenesis and obesity in C57/BL mice," The Journal of Nutrition, vol. 139, no. 5, pp. 919-925, 2009.

[7] S. Egert, A. Bosy-Westphal, J. Seiberl et al., "Quercetin reduces systolic blood pressure and plasma oxidised lowdensity lipoprotein concentrations in overweight subjects with a high-cardiovascular disease risk phenotype: a doubleblinded, placebo-controlled cross-over study," British Journal of Nutrition, vol. 102, no. 7, pp. 1065-1074, 2009.

[8] E. K. Kim, K. B. Kwon, M. Y. Song et al., "Flavonoids protect against cytokine-induced pancreatic $\beta$-cell damage through suppression of nuclear factor $\kappa \mathrm{B}$ activation," Pancreas, vol. 35 , no. 4, pp. e1-e9, 2007.

[9] P. A. Ruiz, A. Braune, G. Hölzlwimmer, L. QuintanillaFend, and D. Haller, "Quercetin inhibits TNF-induced NF$\kappa \mathrm{B}$ transcription factor recruitment to proinflammatory gene promoters in murine intestinal epithelial cells," The Journal of Nutrition, vol. 137, no. 5, pp. 1208-1215, 2007.

[10] S. Martínez-Flórez, B. Gutiérrez-Fernández, S. SánchezCampos, J. González-Gallego, and M. J. Tuñón, "Quercetin attenuates nuclear factor- $\kappa \mathrm{B}$ activation and nitric oxide production in interleukin- $\beta$-activated rat hepatocytes," The Journal of Nutrition, vol. 135, no. 6, pp. 1359-1365, 2005.

[11] L. Rivera, R. Morón, M. Sánchez, A. Zarzuelo, and M. Galisteo, "Quercetin ameliorates metabolic syndrome and improves the inflammatory status in obese Zucker rats," Obesity, vol. 16, no. 9, pp. 2081-2087, 2008.

[12] S. Egert, C. Boesch-Saadatmandi, S. Wolffram, G. Rimbach, and M. J. Müller, "Serum lipid and blood pressure responses to quercetin vary in overweight patients by apolipoprotein E genotype," The Journal of Nutrition, vol. 140, no. 2, pp. 278284, 2010.

[13] E. P. Cherniack, "Polyphenols: planting the seeds of treatment for the metabolic syndrome," Nutrition, vol. 27, no. 6, pp. 617$623,2011$.

[14] C. L. Keen, "Chocolate: food as medicine/medicine as food," Journal of the American College of Nutrition, vol. 20, supplement 5, pp. 436S-439S, 2001.

[15] J. Wollgast and E. Anklam, "Polyphenols in chocolate: is there a contribution to human health?" Food Research International, vol. 33, no. 6, pp. 449-459, 2000.
[16] G. Schinella, S. Mosca, E. Cienfuegos-Jovellanos et al., "Antioxidant properties of polyphenol-rich cocoa products industrially processed," Food Research International, vol. 43, no. 6, pp. 1614-1623, 2010.

[17] T. Hatano, H. Miyatake, M. Natsume et al., "Proanthocyanidin glycosides and related polyphenols from cacao liquor and their antioxidant effects," Phytochemistry, vol. 59, no. 7, pp. 749$758,2002$.

[18] J. H. Weisburger, "Chemopreventive effects of cocoa polyphenols on chronic diseases," Experimental Biology and Medicine, vol. 226, no. 10, pp. 891-897, 2001.

[19] F. M. Steinberg, M. M. Bearden, and C. L. Keen, "Cocoa and chocolate flavonoids: Implications for cardiovascular health," Journal of the American Dietetic Association, vol. 103, no. 2, pp. 215-223, 2003.

[20] C. Sanbongi, N. Suzuki, and T. Sakane, "Polyphenols in chocolate, which have antioxidant activity, modulate immune functions in humans in vitro," Cellular Immunology, vol. 177, no. 2, pp. 129-136, 1997.

[21] T. P. Kenny, C. L. Keen, H. H. Schmitz, and M. E. Gershwin, "Immune effects of cocoa procyanidin oligomers on peripheral blood mononuclear cells," Experimental Biology and Medicine, vol. 232, no. 2, pp. 293-300, 2007.

[22] E. Ramiro, A. Franch, C. Castellote, C. Andrés-Lacueva, M. Izquierdo-Pulido, and M. Castell, "Effect of Theobroma cacao flavonoids on immune activation of a lymphoid cell line," British Journal of Nutrition, vol. 93, no. 6, pp. 859-866, 2005.

[23] E. Ramiro-Puig and M. Castell, "Cocoa: antioxidant and immunomodulator," British Journal of Nutrition, vol. 101, no. 7, pp. 931-940, 2009.

[24] T. Pérez-Berezo, A. Franch, S. Ramos-Romero, C. Castellote, F. J. Pérez-Cano, and M. Castell, "Cocoa-enriched diets modulate intestinal and systemic humoral immune response in young adult rats," Molecular Nutrition and Food Research, vol. 55, supplement 1, pp. S56-S66, 2011.

[25] C. Selmi, T. K. Mao, C. L. Keen, H. H. Schmitz, and M. E. Gershwin, "The anti-inflammatory properties of cocoa flavanols," Journal of Cardiovascular Pharmacology, vol. 47, no. 2, pp. S163-S171, 2006.

[26] G. W. Dryden, M. Song, and C. McClain, "Polyphenols and gastrointestinal diseases," Current Opinion in Gastroenterology, vol. 22, no. 2, pp. 165-170, 2006.

[27] I. Andújar, M. C. Recio, R. M. Giner et al., "Inhibition of ulcerative colitis in mice after oral administration of a polyphenol-enriched cocoa extract is mediated by the inhibition of STAT1 and STAT3 phosphorylation in colon cells," Journal of Agricultural and Food Chemistry, vol. 59, no. 12, pp. 6474-6483, 2011.

[28] W. Ren, Z. Qiao, H. Wang, L. Zhu, and L. Zhang, "Flavonoids: promising anticancer agents," Medicinal Research Reviews, vol. 23, no. 4, pp. 519-534, 2003.

[29] M. Rusconi and A. Conti, "Theobroma cacao L., the food of the Gods: a scientific approach beyond myths and claims," Pharmacological Research, vol. 61, no. 1, pp. 5-13, 2010.

[30] F. A. Tomás-Barberán, E. Cienfuegos-Jovellanos, A. Marín et al., "A new process to develop a cocoa powder with higher flavonoid monomer content and enhanced bioavailability in healthy humans," Journal of Agricultural and Food Chemistry, vol. 55, no. 10, pp. 3926-3935, 2007.

[31] D. D. Mellor, T. Sathyapalan, E. S. Kilpatrick, S. Beckett, and S. L. Atkin, "High-cocoa polyphenol-rich chocolate improves HDL cholesterol in type 2 diabetes patients," Diabetic Medicine, vol. 27, no. 11, pp. 1318-1321, 2010. 
[32] M. Monagas, N. Khan, C. Andres-Lacueva et al., "Effect of cocoa powder on the modulation of inflammatory biomarkers in patients at high risk of cardiovascular disease," American Journal of Clinical Nutrition, vol. 90, no. 5, pp. 1144-1150, 2009.

[33] G. Williamson, "Bioavailability and health effects of cocoa polyphenols," Inflammopharmacology, vol. 17, no. 2, article 111, 2009.

[34] R. R. Holt, S. A. Lazarus, M. C. Sullards et al., "Procyanidin dimer B2 [epicatechin-(4 $\beta-8)$-epicatechin] in human plasma after the consumption of a flavanol-rich cocoa," American Journal of Clinical Nutrition, vol. 76, no. 4, pp. 798-804, 2002.

[35] J. P. E. Spencer, F. Chaudry, A. S. Pannala, S. K. Srai, E. Debnam, and C. Rice-Evans, "Decomposition of cocoa procyanidins in the gastric milieu," Biochemical and Biophysical Research Communications, vol. 272, no. 1, pp. 236-241, 2000.

[36] L. Y. Rios, R. N. Bennett, S. A. Lazarus, C. Rémésy, A. Scalbert, and G. Williamson, "Cocoa procyanidins are stable during gastric transit in humans," American Journal of Clinical Nutrition, vol. 76, no. 5, pp. 1106-1110, 2002.

[37] M. P. Gonthier, J. L. Donovan, O. Texier, C. Felgines, C. Remesy, and A. Scalbert, "Metabolism of dietary procyanidins in rats," Free Radical Biology and Medicine, vol. 35, no. 8, pp. 837-844, 2003.

[38] N. Ortega, J. Reguant, M. P. Romero, A. Macià, and M. J. Motilva, "Effect of fat content on the digestibility and bioaccessibility of cocoa polyphenol by an in vitro digestion model," Journal of Agricultural and Food Chemistry, vol. 57, no. 13, pp. 5743-5749, 2009.

[39] C. Manach, A. Scalbert, C. Morand, C. Rémésy, and L. Jiménez, "Polyphenols: food sources and bioavailability," American Journal of Clinical Nutrition, vol. 79, no. 5, pp. 727$747,2004$.

[40] K. W. Lee, Y. J. Kim, H. J. Lee, and C. Y. Lee, "Cocoa has more phenolic phytochemicals and a higher antioxidant capacity than teas and red wine," Journal of Agricultural and Food Chemistry, vol. 51, no. 25, pp. 7292-7295, 2003.

[41] P. Schroeder, L. O. Klotz, D. P. Buchczyk, C. D. Sadik, T. Schewe, and H. Sies, "Epicatechin selectively prevents nitration but not oxidation reactions of peroxynitrite," Biochemical and Biophysical Research Communications, vol. 285, no. 3, pp. 782-787, 2001.

[42] S. V. Verstraeten, J. F. Hammerstone, C. L. Keen, C. G. Fraga, and P. I. Oteiza, "Antioxidant and membrane effects of procyanidin dimers and trimers isolated from peanut and cocoa," Journal of Agricultural and Food Chemistry, vol. 53, no. 12, pp. 5041-5048, 2005.

[43] P. Martorell, J. V. Forment, R. de Llanos et al., "Use of Saccharomyces cerevisiae and Caenorhabditis elegans as model organisms to study the effect of cocoa polyphenols in the resistance to oxidative stress," Journal of Agricultural and Food Chemistry, vol. 59, no. 5, pp. 2077-2085, 2011.

[44] A. Spadafranca, C. Martínez-Conesa, S. Sirini, and G. Testolin, "Effect of dark chocolate on plasma epicatechin levels, DNA resistance to oxidative stress and total antioxidant activity in healthy subjects," British Journal of Nutrition, vol. 103, no. 7, pp. 1008-1014, 2010.

[45] Y. Gu, W. J. Hurst, D. A. Stuart, and J. D. Lambert, "Inhibition of key digestive enzymes by cocoa extracts and procyanidins," Journal of Agricultural and Food Chemistry, vol. 59, no. 10, pp. 5305-5311, 2011.

[46] K. Hanhineva, R. Törrönen, I. Bondia-Pons et al., "Impact of dietary polyphenols on carbohydrate metabolism,"
International Journal of Molecular Sciences, vol. 11, no. 4, pp. 1365-1402, 2010.

[47] D. Grassi, G. Desideri, S. Necozione et al., "Blood pressure is reduced and insulin sensitivity increased in glucose-intolerant, hypertensive subjects after 15 days of consuming highpolyphenol dark chocolate," The Journal of Nutrition, vol. 138, no. 9, pp. 1671-1676, 2008.

[48] M. G. Shrime, S. R. Bauer, A. C. McDonald, N. H. Chowdhury, C. E. Coltart, and E. L. Ding, "Flavonoid-rich cocoa consumption affects multiple cardiovascular risk factors in a meta-analysis of short-term studies," The Journal of Nutrition, vol. 141, no. 11, pp. 1982-1988, 2011.

[49] L. Hooper, C. Kay, A. Abdelhamid et al., "Effects of chocolate, cocoa, and flavan-3-ols on cardiovascular health: a systematic review and meta-analysis of randomized trials," American Journal of Clinical Nutrition, vol. 95, no. 3, pp. 740-751, 2012.

[50] A. Yasuda, M. Natsume, N. Osakabe, K. Kawahata, and J. Koga, "Cacao polyphenols influence the regulation of apolipoprotein in HepG2 and Caco2 cells," Journal of Agricultural and Food Chemistry, vol. 59, no. 4, pp. 1470-1476, 2011.

[51] N. Khan, M. Monagas, C. Andres-Lacueva et al., "Regular consumption of cocoa powder with milk increases HDL cholesterol and reduces oxidized LDL levels in subjects at high-risk of cardiovascular disease," Nutrition, Metabolism and Cardiovascular Diseases. In press.

[52] L. Jia, X. Liu, Y. Y. Bai et al., "Short-term effect of cocoa product consumption on lipid profile: a meta-analysis of randomized controlled trials," American Journal of Clinical Nutrition, vol. 92, no. 1, pp. 218-225, 2010.

[53] S. Almoosawi, L. Fyfe, C. Ho, and E. Al-Dujaili, "The effect of polyphenol-rich dark chocolate on fasting capillary whole blood glucose, total cholesterol, blood pressure and glucocorticoids in healthy overweight and obese subjects," British Journal of Nutrition, vol. 103, no. 6, pp. 842-850, 2010.

[54] R. Corti, A. J. Flammer, N. K. Hollenberg, and T. F. Lüscher, "Cocoa and cardiovascular health," Circulation, vol. 119, no. 10, pp. 1433-1441, 2009.

[55] M. Gómez-Juaristi, L. González-Torres, L. Bravo, M. P. Vaquero, S. Bastida, and F. J. Sánchez-Muniz, "Beneficial effects of chocolate on cardiovascular health," Nutricion Hospitalaria, vol. 26, no. 2, pp. 289-292, 2011.

[56] O. Khawaja, J. M. Gaziano, and L. Djoussé, "Chocolate and coronary heart disease: a systematic review," Current Atherosclerosis Reports, vol. 13, no. 6, pp. 447-452, 2011.

[57] H. Sies, T. Schewe, C. Heiss, and M. Kelm, "Cocoa polyphenols and inflammatory mediators," The American Journal of Clinical Nutrition, vol. 81, no. 1, supplement, pp. 304S-312S, 2005.

[58] V. B. Schini-Kerth, C. Auger, N. Étienne-Selloum, and T. Chataigneau, "Polyphenol-induced endothelium-dependent relaxations. Role of NO and EDHF," Advances in Pharmacology, vol. 60, pp. 136-175, 2010.

[59] K. W. Lee, N. J. Kang, M. H. Oak et al., "Cocoa procyanidins inhibit expression and activation of MMP-2 in vascular smooth muscle cells by direct inhibition of MEK and MT1MMP activities," Cardiovascular Research, vol. 79, no. 1, pp. 34-41, 2008.

[60] R. Corder, "Red wine, chocolate and vascular health: developing the evidence base," Heart, vol. 94, no. 7, pp. 821-823, 2008.

[61] T. K. Mao, J. van de Water, C. L. Keen, H. H. Schmitz, and M. E. Gershwin, "Cocoa flavonols and procyanidins promote transforming growth factor- $\beta_{1}$ homeostasis in peripheral blood mononuclear cells," Experimental Biology and Medicine, vol. 228, no. 1, pp. 93-99, 2003. 
[62] E. L. Ding, S. M. Hutfless, X. Ding, and S. Girotra, "Chocolate and prevention of cardiovascular disease: a systematic review," Nutrition and Metabolism, vol. 3, article 2, 2006.

[63] K. J. Murphy, A. K. Chronopoulos, I. Singh et al., "Dietary flavanols and procyanidin oligomers from cocoa (Theobroma cacao) inhibit platelet function," American Journal of Clinical Nutrition, vol. 77, no. 6, pp. 1466-1473, 2003.

[64] A. J. Flammer, F. Hermann, I. Sudano et al., "Dark chocolate improves coronary vasomotion and reduces platelet reactivity," Circulation, vol. 116, no. 21, pp. 2376-2382, 2007.

[65] R. Carnevale, L. Loffredo, P. Pignatelli et al., "Dark chocolate inhibits platelet isoprostanes via NOX2 down-regulation in smokers," Journal of Thrombosis and Haemostasis, vol. 10, no. 1, pp. 125-132, 2012.

[66] M. Galleano, O. Pechanova, and C. G. Fraga, "Hypertension, nitric oxide, oxidants, and dietary plant polyphenols," Current Pharmaceutical Biotechnology, vol. 11, no. 8, pp. 837-848, 2010.

[67] E. Cienfuegos-Jovellanos, M. Del Mar Quiñones, B. Muguerza, L. Moulay, M. Miguel, and A. Aleixandre, "Antihypertensive effect of a polyphenol-rich cocoa powder industrially processed to preserve the original flavonoids of the cocoa beans," Journal of Agricultural and Food Chemistry, vol. 57, no. 14, pp. 6156-6162, 2009.

[68] M. Akita, M. Kuwahara, F. Itoh et al., "Effects of cacao liquor polyphenols on cardiovascular and autonomic nervous functions in hypercholesterolaemic rabbits," Basic and Clinical Pharmacology and Toxicology, vol. 103, no. 6, pp. 581-587, 2008.

[69] G. Rimbach, M. Melchin, J. Moehring, and A. E. Wagner, "Polyphenols from cocoa and vascular health-a critical review," International Journal of Molecular Sciences, vol. 10, no. 10, pp. 4290-4309, 2009.

[70] K. Ried, O. R. Frank, and N. P. Stocks, "Dark chocolate or tomato extract for prehypertension: a randomised controlled trial," BMC Complementary and Alternative Medicine, vol. 9, article 22, 2009.

[71] D. Grassi, G. Desideri, and C. Ferri, "Blood pressure and cardiovascular risk: what about cocoa and chocolate?" Archives of Biochemistry and Biophysics, vol. 501, no. 1, pp. 112-115, 2010.

[72] L. Actis-Goretta, J. I. Ottaviani, and C. G. Fraga, "Inhibition of angiotensin converting enzyme activity by flavanol-rich foods," Journal of Agricultural and Food Chemistry, vol. 54, no. 1, pp. 229-234, 2006.

[73] S. Desch, J. Schmidt, D. Kobler et al., "Effect of cocoa products on blood pressure: systematic review and meta-analysis," American Journal of Hypertension, vol. 23, no. 1, pp. 97-103, 2010.

[74] E. Ramiro, A. Franch, C. Castellote et al., "Flavonoids from Theobroma cacao down-regulate inflammatory mediators," Journal of Agricultural and Food Chemistry, vol. 53, no. 22, pp. 8506-8511, 2005.

[75] W. Y. Zhang, H. Q. Liu, K. Q. Xie et al., "Procyanidin dimer B2 [epicatechin-(4 $\beta-8)$-epicatechin] suppresses the expression of cyclooxygenase-2 in endotoxin-treated monocytic cells," Biochemical and Biophysical Research Communications, vol. 345, no. 1, pp. 508-515, 2006.

[76] B. Romier, Y. J. Schneider, Y. Larondelle, and A. During, "Dietary polyphenols can modulate the intestinal inflammatory response," Nutrition Reviews, vol. 67, no. 7, pp. 363-378, 2009.

[77] B. Romier-Crouzet, J. van de Walle, A. During et al., "Inhibition of inflammatory mediators by polyphenolic plant extracts in human intestinal Caco-2 cells," Food and Chemical Toxicology, vol. 47, no. 6, pp. 1221-1230, 2009.

[78] M. Vázquez-Agell, M. Urpi-Sarda, E. Sacanella et al., "Cocoa consumption reduces NF- $\kappa \mathrm{B}$ activation in peripheral blood mononuclear cells in humans," Nutrition, Metabolism and Cardiovascular Diseases. In press.

[79] H. Shapiro, P. Singer, Z. Halpern, and R. Bruck, "Polyphenols in the treatment of inflammatory bowel disease and acute pancreatitis," Gut, vol. 56, no. 3, pp. 426-436, 2007.

[80] M. Yamagishi, N. Osakabe, M. Natsume et al., "Anticlastogenic activity of cacao: inhibitory effect of cacao liquor polyphenols against mitomycin C-induced DNA damage," Food and Chemical Toxicology, vol. 39, no. 12, pp. 1279-1283, 2001.

[81] E. S. Cho, K. W. Lee, and H. J. Lee, "Cocoa procyanidins protect PC12 cells from hydrogen-peroxide-induced apoptosis by inhibiting activation of p38 MAPK and JNK," Mutation Research, vol. 640, no. 1-2, pp. 123-130, 2008.

[82] I. Rodríguez-Ramiro, S. Ramos, E. López-Oliva et al., “Cocoarich diet prevents azoxymethane-induced colonic preneoplastic lesions in rats by restraining oxidative stress and cell proliferation and inducing apoptosis," Molecular Nutrition and Food Research, vol. 55, no. 12, pp. 1895-1899, 2011.

[83] M. A. Martín, S. Ramos, R. Mateos et al., "Protection of human HepG2 cells against oxidative stress by cocoa phenolic extract," Journal of Agricultural and Food Chemistry, vol. 56, no. 17, pp. 7765-7772, 2008.

[84] D. E. Lee, N. J. Kang, K. M. Lee et al., "Cocoa polyphenols attenuate hydrogen peroxide-induced inhibition of gapjunction intercellular communication by blocking phosphorylation of connexin 43 via the MEK/ERK signaling pathway," The Journal of Nutritional Biochemistry, vol. 21, no. 8, pp. 680$686,2010$.

[85] S. Carnésecchi, Y. Schneider, S. A. Lazarus, D. Coehlo, F. Gossé, and F. Raul, "Flavanols and procyanidins of cocoa and chocolate inhibit growth and polyamine biosynthesis of human colonic cancer cells," Cancer Letters, vol. 175, no. 2, pp. 147-155, 2002.

[86] M. Ohno, K. Q. Sakamoto, M. Ishizuka, and S. Fujita, "Crude cacao Theobroma cacao extract reduces mutagenicity induced by benzo[a]pyrene through inhibition of CYP1A activity in vitro," Phytotherapy Research, vol. 23, no. 8, pp. 1134-1139, 2009.

[87] C. Oleaga, M. García, A. Solé, C. J. Ciudad, M. IzquierdoPulido, and V. Noé, "CYP1A1 is overexpressed upon incubation of breast cancer cells with a polyphenolic cocoa extract," European Journal of Nutrition, vol. 51, no. 4, pp. 465-476, 2012.

[88] N. J. Kang, K. W. Lee, D. E. Lee et al., “Cocoa procyanidins suppress transformation by inhibiting mitogen-activated protein kinase kinase," The Journal of Biological Chemistry, vol. 283, no. 30, pp. 20664-20673, 2008.

[89] J. E. Kim, J. E. Son, S. K. Jung et al., "Cocoa polyphenols suppress TNF- $\alpha$-induced vascular endothelial growth factor expression by inhibiting phosphoinositide 3-kinase (PI3K) and mitogen-activated protein kinase kinase-1 (MEK1) activities in mouse epidermal cells," British Journal of Nutrition, vol. 104, no. 7, pp. 957-964, 2010.

[90] G. F. Ferrazzano, I. Amato, A. Ingenito, A. de Natale, and A. Pollio, "Anti-cariogenic effects of polyphenols from plant stimulant beverages (cocoa, coffee, tea)," Fitoterapia, vol. 80, no. 5, pp. 255-262, 2009.

[91] T. Tomofuji, D. Ekuni, K. Irie et al., "Preventive effects of a cocoa-enriched diet on gingival oxidative stress in 
experimental periodontitis," Journal of Periodontology, vol. 80, no. 11, pp. 1799-1808, 2009.

[92] T. K. Mao, J. van de Water, C. L. Keen, H. H. Schmitz, and M. E. Gershwin, "Effect of cocoa flavanols and their related oligomers on the secretion of interleukin- 5 in peripheral blood mononuclear cells," Journal of Medicinal Food, vol. 5, no. 1, pp. $17-22,2002$.

[93] D. L. Katz, K. Doughty, and A. Ali, "Cocoa and chocolate in human health and disease," Antioxidant and Redox Signaling, vol. 15, no. 10, pp. 2779-2811, 2011.

[94] T. Sathyapalan, S. Beckett, A. S. Rigby, D. D. Mellor, and S. L. Atkin, "High cocoa polyphenol rich chocolate may reduce the burden of the symptoms in chronic fatigue syndrome," Nutrition Journal, vol. 9, no. 1, article 55, 2010.

[95] J. F. Bisson, A. Nejdi, P. Rozan, S. Hidalgo, R. Lalonde, and M. Messaoudi, "Effects of long-term administration of a cocoa polyphenolic extract (Acticoa powder) on cognitive performances in aged rats," British Journal of Nutrition, vol. 100, no. 1, pp. 94-101, 2008.

[96] F. K. Addai, "Natural cocoa as diet-mediated antimalarial prophylaxis," Medical Hypotheses, vol. 74, no. 5, pp. 825-830, 2010.

[97] P. Gasser, E. Lati, L. Peno-Mazzarino, D. Bouzoud, L. Allegaert, and H. Bernaert, "Cocoa polyphenols and their influence on parameters involved in ex vivo skin restructuring," International Journal of Cosmetic Science, vol. 30, no. 5, pp. 339-345, 2008.

[98] R. Mukai, I. Fukuda, S. Nishiumi et al., "Cacao polyphenol extract suppresses transformation of an aryl hydrocarbon receptor in C57BL/6 mice," Journal of Agricultural and Food Chemistry, vol. 56, no. 21, pp. 10399-10405, 2008. 


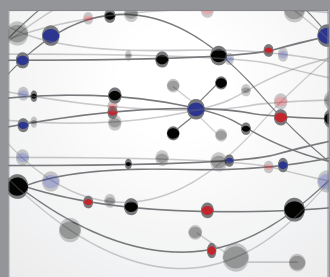

The Scientific World Journal
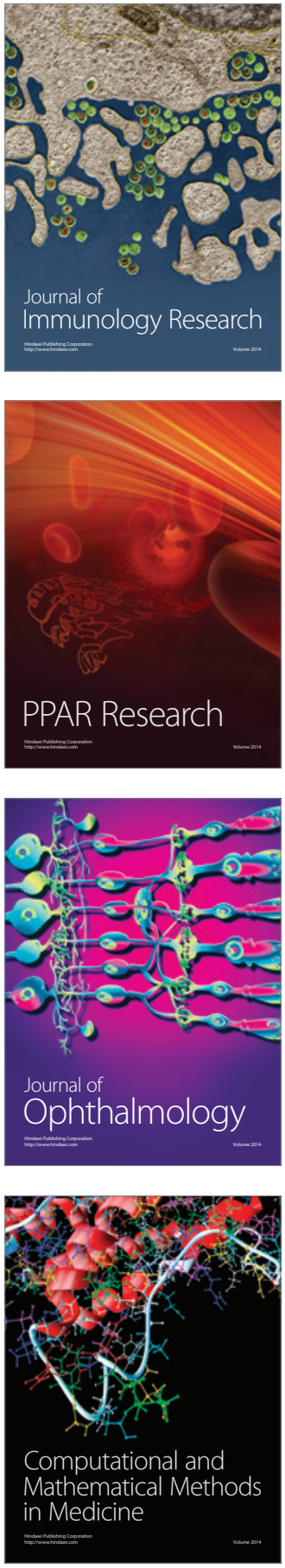

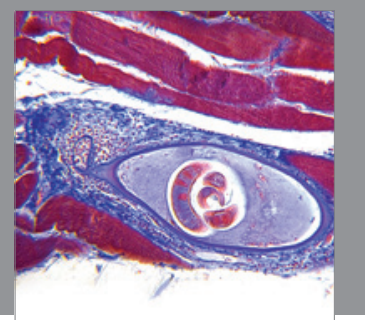

Gastroenterology

Research and Practice
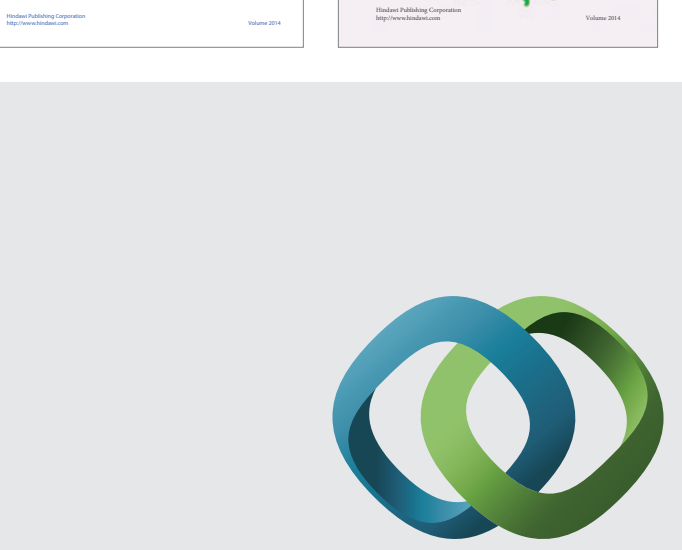

\section{Hindawi}

Submit your manuscripts at

http://www.hindawi.com
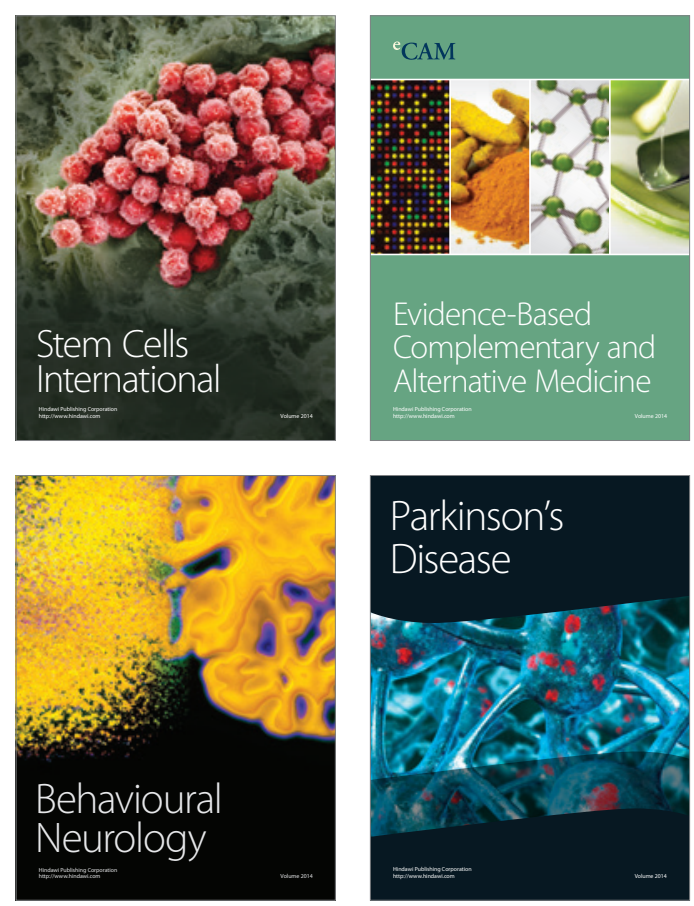

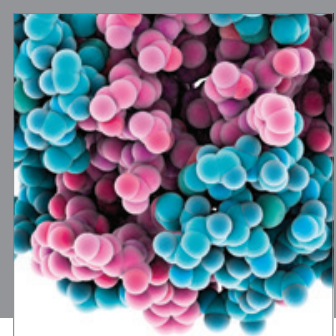

Journal of
Diabetes Research

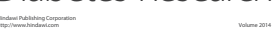

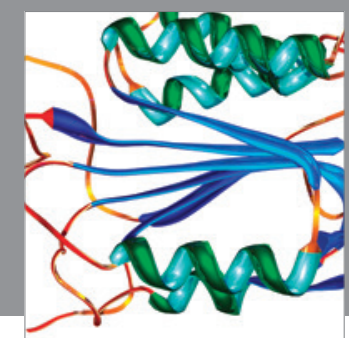

Disease Markers
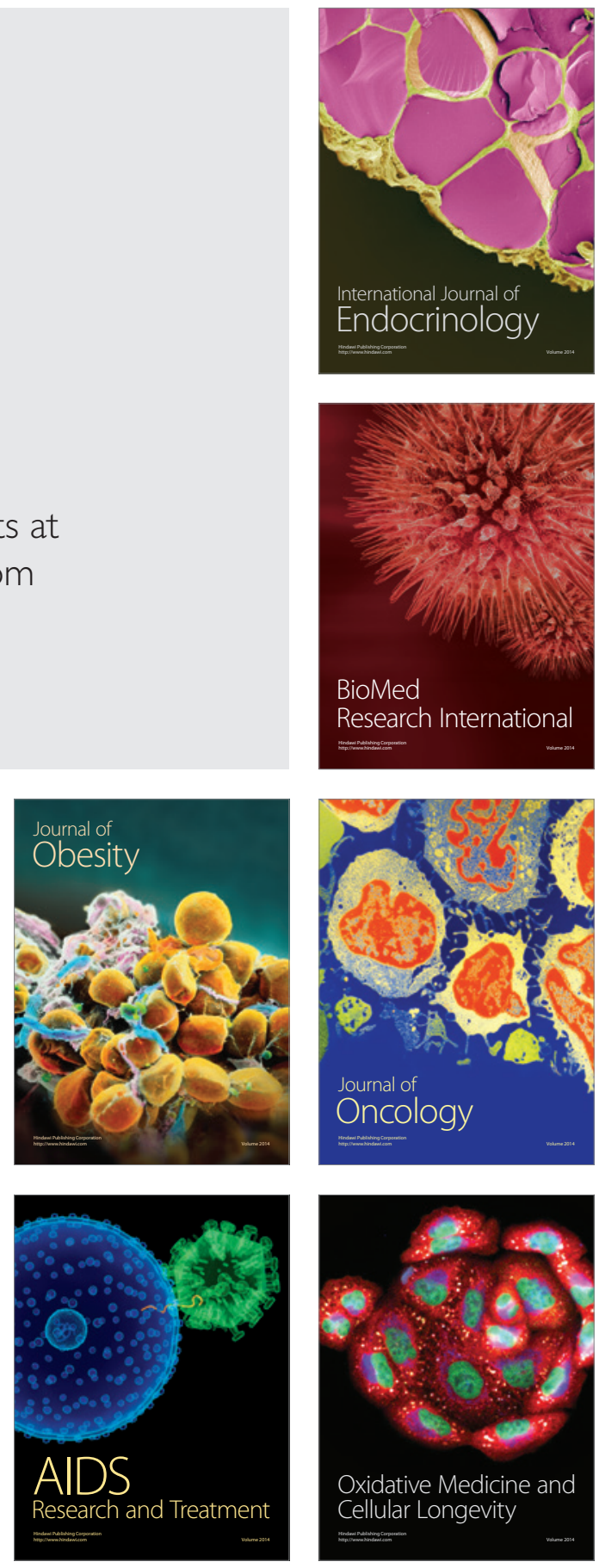